Article

\title{
Bioreactor Processed Stromal Cell Seeding and Cultivation on Decellularized Pericardium Patches for Cardiovascular Use
}

\author{
Roman Matějka ${ }^{1,2,3, *} \oplus$, Miroslav Koňařík ${ }^{4,5}$, Jana Štěpanovská ${ }^{1,2}{ }^{\oplus}$, Jan Lipenský ${ }^{6}$, \\ Jaroslav Chlupáč ${ }^{2,7,8} \mathbb{C}^{\text {, Daniel Turek }}{ }^{4,5}$, Šimon Pražák ${ }^{1,2}$, Antonín Brož ${ }^{2} \mathbb{D}_{\text {, }}$ \\ Zuzana Šimůnková ${ }^{9}$, Iveta Mrázová ${ }^{9}$, Serhiy Forostyak ${ }^{6,10}$, Peter Kneppo ${ }^{1} \mathbb{D}$, Jozef Rosina ${ }^{1,3}$, \\ Lucie Bačáková ${ }^{2}$ (1) and Jan Pirk ${ }^{4}$
}

1 Department of Biomedical Technology, Faculty of Biomedical Engineering, Czech Technical University in Prague, 27201 Kladno, Czech Republic; jana.stepanovska@fbmi.cvut.cz (J.Š.); simon.prazak@fgu.cas.cz (Š.P.); kneppo@fbmi.cvut.cz (P.K.); rosina@fbmi.cvut.cz (J.R.)

2 Department of Biomaterials and Tissue Engineering, Institute of Physiology of the Czech Academy of Sciences, 14220 Prague, Czech Republic; jaroslav.chlupac@ikem.cz (J.C.); antonin.broz@fgu.cas.cz (A.B.); lucie.bacakova@fgu.cas.cz (L.B.)

3 Department of Medical Biophysics and Informatics, Third Faculty of Medicine, Charles University in Prague, 10000 Prague, Czech Republic

4 Cardiovascular Surgery Department, Institute for Clinical and Experimental Medicine, 14021 Prague, Czech Republic; miroslav.konarik@ikem.cz (M.K.); daniel.turek@ikem.cz (D.T.); jan.pirk@ikem.cz (J.P.)

5 Institute of Physiology, First Faculty of Medicine, Charles University in Prague, 12108 Prague, Czech Republic

6 PrimeCell Bioscience a.s., 11000 Prague, Czech Republic; jan.lipensky@primecell.eu (J.L.); serhiy.forostyak@primecell.eu (S.F.)

7 Transplant Surgery Department, Institute for Clinical and Experimental Medicine, 14021 Prague, Czech Republic

8 Department of Anatomy, Second Faculty of Medicine, Charles University in Prague, 15006 Prague, Czech Republic

9 Experimental Medicine Centre, Institute for Clinical and Experimental Medicine, 14021 Prague, Czech Republic; zuzana.simunkova@ikem.cz (Z.Š.); iveta.mrazova@ikem.cz (I.M.)

10 Department of Burns and Plastic Surgery, Faculty of Medicine, Masaryk University, 62500 Brno, Czech Republic

* Correspondence: roman.matejka@fbmi.cvut.cz; Tel.: +42-02-2435-9936

Received: 21 July 2020; Accepted: 5 August 2020; Published: 7 August 2020

Featured Application: In this study, we have prepared decellularized pericardium repopulated with adipose tissue-derived stromal cells for potential use as implantable cardiovascular patches. Novel optimized dynamic decellularization and recellularization systems have been used and demonstrated. In this bioreactor, the stromal cells deeply repopulated the full thickness of the matrix, and they pre-differentiated towards the smooth muscle cell phenotype by applying cyclic pressure stimulation. Thus, these dynamically recellularized patches resemble vascular tunica media. These grafts may be further applied in animal experiments to assess surface endothelialization and in vivo remodelling. Animal tissue is of large potential availability and decellularization renders the matrix non-immunogenic. Autologous adipose cells for recellularization can be harvested through small biopsy in human patients with cardiovascular disease. A potential application of this approach is manufacturing a tissue-engineered cardiovascular patch with improved biocompatibility for the surgical repair of the human heart or vessels, such as the carotid artery or femoral artery. 
Abstract: (1) Background: Decellularized xenogeneic tissues are promising matrices for developing tissue-engineered cardiovascular grafts. In vitro recellularization of these tissues with stromal cells can provide a better in vivo remodelling and a lower thrombogenicity of the graft. The process of recellularization can be accelerated using a cultivation bioreactor simulating physiological conditions and stimuli. (2) Methods: Porcine pericardium was decellularized using a custom-built decellularization system with an optimized protocol. Autologous porcine adipose-derived stromal cells (PrASCs), isolated from the subcutaneous fat tissue, were used for recellularizing the decellularized pericardium. A custom cultivation bioreactor allowing the fixing of the decellularized tissue into a special cultivation chamber was created. The bioreactor maintained micro-perfusion and pulsatile pressure stimulation in order to promote the ingrowth of PrASCs inside the tissue and their differentiation. (3) Results: The dynamic cultivation promoted the ingrowth of cells into the decellularized tissue. Under static conditions, the cells penetrated only to the depth of $50 \mu \mathrm{m}$, whereas under dynamic conditions, the tissue was colonized up to $250 \mu \mathrm{m}$. The dynamic cultivation also supported the cell differentiation towards smooth muscle cells (SMCs). In order to ensure homogeneous cell colonization of the decellularized matrices, the bioreactor was designed to allow seeding of the cells from both sides of the tissue prior to the stimulation. In this case, the decellularized tissue was recolonized with cells within 5 days of dynamic cultivation. (4) Conclusions: Our newly designed dynamic bioreactor markedly accelerated the colonization of decellularized pericardium with ASCs and cell differentiation towards the SMC phenotype.

Keywords: bioreactor; cardiovascular patch; decellularization; recellularization; pericardium

\section{Introduction}

Cardiovascular diseases belong to the most frequent causes of death or life quality impairment. Currently, autologous vessel replacements such as the saphenous vein represent the gold standard grafts for small-diameter vessels (below $6 \mathrm{~mm}$ ), and in many factors, they outperform synthetic alternatives. Autologous grafts, however, are of limited availability, and an invasive approach for their harvesting is required. In many cases, they are unsuitable for use due to unfavorable anatomy (gracility, branching, thrombosis) or previous harvest [1]. Allograft vessels from cadaveric donors provide an alternative source for bypass grafting. These grafts can be cold-stored or cryopreserved in tissue banks; nevertheless, they are not immediately available for emergent surgery, and also their long-term patency is limited [2]. Synthetic grafts act in many cases as suitable replacements; however, they show a reduced clinical efficacy, especially in small-calibre applications [3]. There is a great clinical demand for new biomaterials providing feasible solutions, including proper mechanical support, functional tissue regeneration, and a non-thrombogenic surface [4].

Not only tubular grafts but also planar patches are required with similar properties as cardiovascular prostheses [5]. These planar patches are indispensable in many vascular reconstruction procedures, i.e., endarterectomy [6].

Moreover, with pliable, non-thrombogenic, non-immunogenic patches seeded with autologous cells, we are just one step ahead of new heart valves' construction. Current heart valve bioprostheses, despite various types of advanced anti-calcification processing, are still subject to structural valve deterioration (SVD) in a long-term manner. The incidence of SVD is strongly dependent on age and the type of prosthesis, so it can vary widely between $3.3-20 \%$ at a 10 -year follow up, even in the elderly population [7]. SVD strongly limits the clinical use of bioprosthetic valves in younger patients, especially in children.

One possible solution to this problem is using xenogeneic grafts. However, animal tissues cannot be directly applied due to immune incapability, risk of infectious disease transfer, and other safety and regulatory issues. Therefore, a need for tissue processing and engineering is a crucial step 
toward practical application. One possible way is graft decellularization. This process removes the immunogenic cellular elements and produces a non-immunogenic substitute suitable as an implantable graft or scaffold for further modifications. Also, the mechanical strength is preserved similarly to the native blood vessel, which is suitable for recolonization with the recipient's native cells in vivo [8,9].

The decellularization is typically accomplished by treating the tissues with a combination of detergents, solvents, enzymes, osmotic gradients, and chelating agents $[10,11]$. The process of decellularization affects the structural and functional features of the tissue, such as its swelling and stretching properties, suture retention, and the conductivity for cells [12]. Decellularized matrices for cardiovascular use need further modification. The first major thing is to improve the antithrombogenicity. Second is the support of an overall cell recolonization and stimulate re-endothelization in vivo. These steps could involve chemical modifications employing growth factors such as VEGF (Vascular endothelial growth factor), bFGF (Basic fibroblast growth factor) [13] to promote cell overgrowth, or use of heparin as an anti-thrombogenic agent, which also promotes cell grow [14]. On the other hand, growth factor use can be problematic for fulfilling the regulatory requirements for tissue grafts intended for human use and also potentially can induce unpredictable cell growth of host cells.

The second approach to the modification of decellularized matrices is their recolonization with cells. Several studies have demonstrated the improved performance of these matrices in animal models. Cell-recolonized decellularized grafts are distinguished by better biocompatibility, growth potential, mechanical strength, and elasticity. They also reduce the risk of thrombus formation and calcification and induce the recruitment of progenitor cells and tissue regeneration in vivo in contrast to the artificial materials [12]. These studies often used smooth muscle cells (SMCs) or endothelial cells (ECs) or their combinations [15], or included the adipose tissue-derived stromal cells (ASCs) [16]. One of the advantages of ASCs is their high yield and high differentiation potential in comparison with differentiated cells [17]. Another advantage is the easiness of isolation, either from the liposuction-derived or excision-derived adipose tissue when compared to SMC or EC. These allow isolation of autologous cells for combined use with decellularized grafts. Dynamic cultivation of stem or stromal cells is an essential tool for promoting their proliferation, but also for inducing and establishing a contractile differentiated SMC-like phenotype in these cells. The differentiation of stem cells towards SMCs requires pulsatile stress and cyclic strain, which are components of the hemodynamic stress to which the blood vessels are exposed in vivo [18].

Conventional preparation of recellularized grafts is time-consuming. Under the static conditions, it takes several weeks of cell cultivation to reach cell overgrowth and maturation toward differentiated cells/tissues [15]. Dynamic bioreactors mimicking physiological conditions could speed-up recellularization and promote cell differentiation.

In this study, we demonstrate a novel cultivation system allowing the recellularization of planar decellularized tissues intended as cardiovascular patches. This system incorporates a combination of micro-perfusion with mechanical strain to stimulate the proliferation of ASC cells and their differentiation towards smooth muscle cells. As for substrate, we have used two types of decellularized tissues-porcine and ovine decellularized pericardium. With possible use in in vivo conditions, the porcine pericardium will be acting as allogenous decellularized tissue, and the ovine will be modelling xenogeneic decellularized tissue.

\section{Materials and Methods}

\subsection{Porcine and Ovine Pericardium for Decellularization}

The porcine pericardium was obtained from a local slaughterhouse (Steinhauser s.r.o, Skalice nad Svitavou, Czech Republic). The Large White breed of pigs with a weight of approximately $100 \mathrm{~kg}$ and age 5-6 months were used. The fresh tissues were extracted during the slaughter process. The tissue was then transported to our laboratory in phosphate-buffered saline (PBS) with $100 \mu \mathrm{g} / \mathrm{mL}$ Gentamicin and $10 \mu \mathrm{g} / \mathrm{mL}$ Fluconazole (both LEK PHARMACEUTICAL D.D., Ljubljana, Slovenia). 
In the laboratory, the pericardial tissue was mechanically cleaned from fat and other residues. Then the tissue was cut into smaller pieces (approx. $6 \times 10 \mathrm{~cm}$ ) to fit into the decellularization chamber described below, and frozen in a DMEM (Dulbecco's Modified Eagle Medium) medium with 10\% FBS (Fetal Bovine Serum), 1\% ABAM (Antibiotic Antimycotic Solution, contains 100 units penicillin, $0.1 \mathrm{mg}$ streptomycin, and $0.25 \mu \mathrm{g}$ amphotericin B per $\mathrm{ml}$ of culture media) and $10 \%$ DMSO (Dimethyl sulfoxide). The freezing gradient was set to $1{ }^{\circ} \mathrm{C} / \mathrm{min}$ up to $-80^{\circ} \mathrm{C}$. All chemicals unless otherwise specified were from Sigma-Aldrich (Sigma-Aldrich, St. Louis, MO, USA).

The ovine pericardium was obtained from experimental sheep (Suffolk breed, animals were used for another experimental work; these tissues were harvested fulfilling 3R). After animals were euthanized, a median sternotomy was performed and was followed by thoracotomy. The pericardium was extracted and mechanically cleaned from surrounding tissue, mainly fat. The same protocol for handling and cryopreservation, as described above, was used. Due to a limited number of experimental sheep, optimization procedures were mainly done on the porcine pericardium.

\subsection{Decellularization System and Pericardium Decellularization}

To automate the overall process of decellularization, a custom-made decellularization system was built. This solution consists of two peristaltic pumps with attached pinch valves. This system is controlled by an embedded controller compactRIO (National Instruments, Austin, TX, USA) with custom LabVIEW (also National Instruments) software to set appropriate parameters of the decellularization and to monitor the overall process. The first pump mixes and prepares decellularization agents, such as SDS (Sodium dodecyl sulfate) or DNAse, with $\mathrm{dH}_{2} \mathrm{O}$ (deionized water) and fills the decellularization chamber. The second pump maintains the recirculation of the agents in the decellularization chamber. This approach promotes the overall decellularization of large tissues.

The process of decellularization works in cycles. First, the decellularization agent or water is filled into the chamber. Then, the agent/water is recirculated for a defined period. After that, the agent/water is flushed into waste. Finally, a new agent or water is filled again. These steps are repeated depending on the tissue properties or experimental setup. This multicycle approach maintains a high chemical gradient promoting the efficiency of agents and washing. The system is installed in a heated chamber that holds the temperature to $37^{\circ} \mathrm{C}$. Higher temperature promotes the activity of detergents. Also, a special chamber was designed for fixing the planar pericardial tissue. The flow in this chamber is optimized to be homogeneously spread over both sides of the tissue. This helps to decellularize the tissue homogenously and to avoid the persistence of non-decellularized areas. The tissue in this chamber is fixed on a silicone holder using surgical silk. The overall view of the decellularization system and the fixing chamber is in Figure 1. 

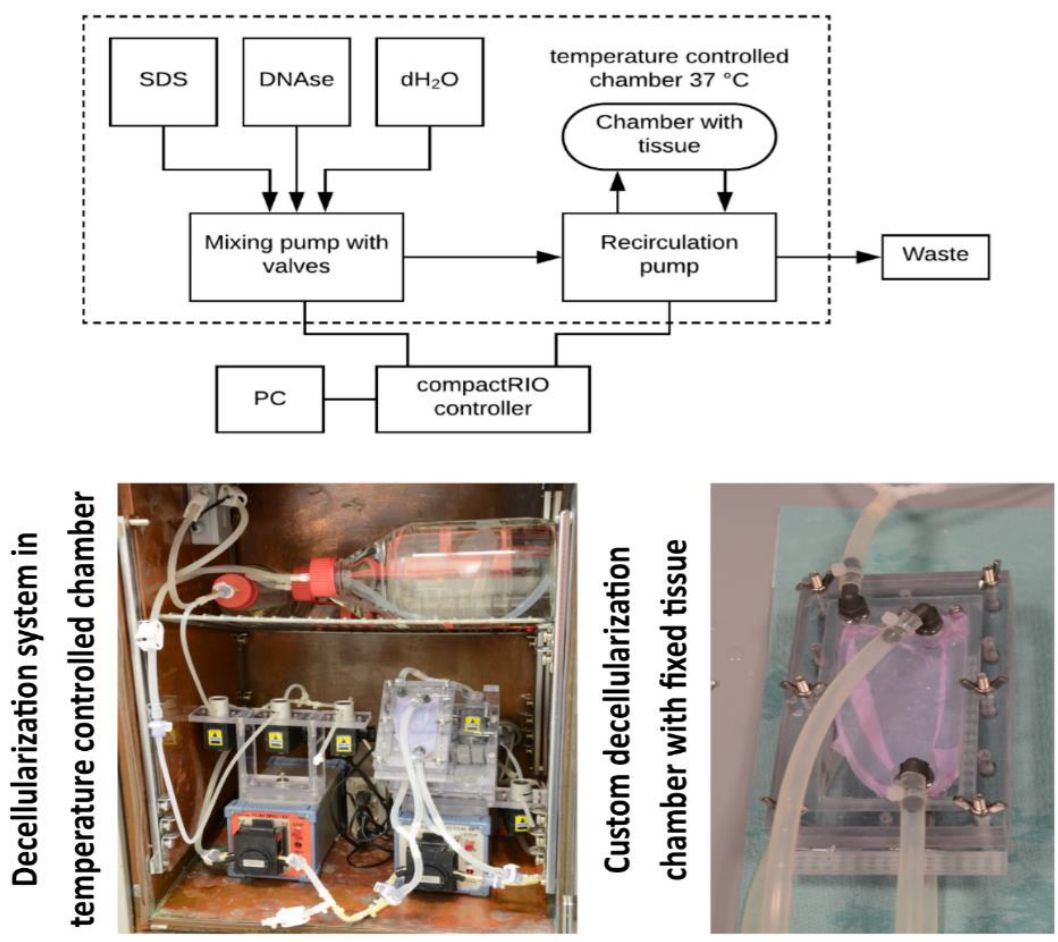

Figure 1. Schematic image of the decellularization system (top) and its installation in a temperature-controlled chamber (bottom left). Custom chamber for fixing pericardium and for maintaining the optimal process parameters (bottom right). The tissue is fixed in the chamber using a $4-0$ suture on a silicone holder.

The frozen pericardium was thawed in a $37^{\circ} \mathrm{C}$ water bath. Then, the tissue was installed in the decellularization chamber using a $4-0$ suture. The $0.5 \%$ SDS solution was used as a decellularization agent. This solution was used in 6 recirculation cycles lasting $10 \mathrm{~min}$ each. Then the SDS was washed out using 5 recirculation cycles of $\mathrm{dH}_{2} \mathrm{O}$ lasting 5 min each. After that, a 60 min-lasting DNAse cycle was performed. The DNAse was dissolved in a DNAse buffer to the concentration of $40 \mu \mathrm{g} / \mathrm{mL}$. This treatment was crucial to remove the remaining residues of DNA spilt over the tissue as a result of the previous SDS treatment. Then, the overall process was finished with a thorough washing of the tissue, consisting of a hundred 10-min cycles of $\mathrm{dH}_{2} \mathrm{O}$. The agent concentration, the cycle repetitions, and the exposure times were optimized to neutralize the potentially toxic effects of the agents and to minimize the mechanical degradation of the tissue described earlier [19]. The decellularized tissues were then sterilized in a 70\% ethanol solution for $1 \mathrm{~h}$, and then they were rinsed and stored in sterile PBS at $4{ }^{\circ} \mathrm{C}$. To evaluate the effectiveness of the decellularization process, $10 \mu \mathrm{m}$-thin cryosections from randomly selected parts of the tissues were prepared. These sections were stained using DAPI to visualize the cell nuclei or the remaining DNA.

Cytotoxicity and sterility tests were also performed. The cultivation of cells in the leachate and directly on the decellularized tissue were done to verify the potential cytotoxic effects. The leachates were prepared in a laboratory. Decellularized and sterile tissue was incubated in DMEM culture media with 10\% FBS for $72 \mathrm{~h}$. Then, this culture media was added to cells, and proliferation was observed. The isolated porcine adipose tissue-derived stromal cells were used for these cytotoxic tests. The sterility tests were performed according to Ph. eur. 2.6.1 and ISO 11737-2 [20] in thioglycollate broth and tryptic soy broth.

\subsection{Fat Extraction and Isolation of Porcine Adipose-Derived Stromal Cells}

Porcine adipose tissue-derived stromal cells (PrASCs) were isolated from fat that was surgically extracted from the neck area of experimental pigs. Prestice black-pied pigs weighing approximately $35-40 \mathrm{~kg}$ were used. 
During the surgery under general anaesthesia, a small amount of subcutaneous fat (approx. $2 \mathrm{~cm}^{3}$ ) was excised. Harvesting subcutaneous fat from the neck area was an easy and rapid surgical procedure well tolerated by the animals. There were no complications regarding wound healing. The fat obtained from this procedure was stored in warm DMEM containing 10\% FBS and 3\% ABAM solution and was transferred to the laboratory for further cell isolation.

The protocol for cell isolation was set according to Estes et al. [21] with some modifications developed in studies focused on adipose-derived stem or stromal cells [22,23]. These modifications included tissue homogenization and a red blood cell lysing step. First, the fat tissue was mechanically cleaned from other tissues and was rinsed several times in PBS with 3\% ABAM solution. Then, the fat was mechanically minced and homogenized into small pieces, and put into a $0.1 \%$ collagenase I solution with 1\% BSA in PBS. After $2 \mathrm{~h}$ of collagenase digestion, the cells were treated with a red blood cell lysis buffer, centrifuged, and seeded into cultivation flasks with DMEM with 15\% FBS and 1\% ABAM solution. In these primocultures, it took approximately 3-5 days to reach the cell confluence, which was taken as passage 0 . After that, the cells were passaged into large $175 \mathrm{~cm}^{2}$ culture flasks (1.2-1.5 million of cells per flask) and cultivated in a DMEM/F12 medium (ratio 1:1) supplemented with 10\% FBS, $10 \mathrm{ng} / \mathrm{mL}$ FGF2 (FGF-basic (154aa), Genscript, Leiden, The Netherlands) and 1\% ABAM solution. This medium was used to stimulate cell proliferation. After reaching confluence in passage 1, the cells were seeded on the decellularized pericardium. In addition, a flow cytometry analysis was performed to characterize the cells. The cells in the 2nd passage were also characterized by a flow cytometry analysis using NovoCyte Flow Cytometer (Acea Biosciences, Inc., CA, USA). Results of flow cytometry shown in Table 1.

Table 1. Flow cytometry analysis of isolated adipose-derived stromal cells.

\begin{tabular}{ccccc}
\hline CD Marker & PrASC Animal 1 & PrASC Animal 2 & Antibody Provider & Cat. No. \\
\hline 29 & $98.85 \%$ & $99.34 \%$ & Invitrogen (CA, USA) & CD2920 \\
31 & $34.58 \%$ & $28.64 \%$ & Origene (MD, USA) & SM2146APC \\
34 & $0.47 \%$ & $1.06 \%$ & Biorbyt (UK) & orb247244 \\
45 & $1.09 \%$ & $2.99 \%$ & Biorad (CA, USA) & MCA1222A647 \\
73 & $0.31 \%$ & $2.60 \%$ & Biolegend (CA, USA) & 344004 \\
90 & $99.08 \%$ & $99.64 \%$ & BD Biosciences (NJ, USA) & 555596 \\
105 & $96.23 \%$ & $99.56 \%$ & Abcam (UK) & ab53321 \\
146 & $0.18 \%$ & $0.71 \%$ & Origene (MD, USA) & SM1860F \\
\hline
\end{tabular}

\subsection{Cultivation Bioreactor}

A custom-made dynamic culture system was used for recellularization of the decellularized tissue. This system consists of a specially designed cultivation chamber that allows fixing the pericardium, and of a pressure stimulation system generating pressure pulsation and culture media perfusion.

The cultivation chamber consists of four main parts. The middle two parts create a tissue holder. Both parts create reservoirs for culture media, and also, one part contains a small silicone gasket fixing the tissue. The decellularized tissue is cut to $35 \times 35 \mathrm{~mm}^{2}$ squares. Then these squares are placed over the hole of the reservoir. The reservoir has a square shape and is limiting the area to $30 \times 30 \mathrm{~mm}^{2}$ where cells are cultivated. The remaining $2.5 \mathrm{~mm}$ border of the prepared tissues is used for fixing them in place. A special inlet is put into this hole in order to prevent tissue bending. Then, the tissue is fixed with the second middle part of the chamber containing the silicone gasket that fixes the tissue in its position. A silicone O-ring gasket is also added to ensure the tightness of the chamber. Four stainless steel M4 screws tighten the holder. After this procedure, the helping inlet is removed.

Next, the chamber is closed by covers containing fluidics ports. Two more silicone O-ring gaskets are added to ensure the tightness. These covers are also tightened to the holder using stainless steel M4 screws with knurled nuts. To minimize the risk of any contamination or toxicity, these screws are not in contact with the tissue or the culture media. All other parts of the chamber are made of non-toxic materials including polycarbonate, polyamide, or silicone as mentioned above, and were 
previously tested for potential cytotoxicity. Fluidics ports include two elbow pieces with silicone hoses with Luer-Locks (LLs) or quick couplings for connecting the perfusion/stimulation system. There are also two female LLs located in the middle of the lid for connecting a sterile septum for cell seeding, auxiliary hoses for pressure sensing, etc. The overall view of the cultivation chamber and its sections are illustrated in Figure 2. The technical solution is described in detail in our utility model [24].

After assembling the chamber and ensuring its tightness, the chamber is connected to a perfusion circuit, a syringe with cultivation media and a working reservoir (described below). All the above-mentioned steps (i.e., tissue fixing, chamber assembling, connecting to perfusion circuit, etc.) are done in a biohazard box to ensure sterility. The cell seeding is then done using the sterile septum and a syringe with a needle. The chamber is vertically oriented during cultivation to minimize the risk of forming bubbles in the reservoirs. In order to provide multiple parallel sample cultivation, the chambers were daisy-chained.
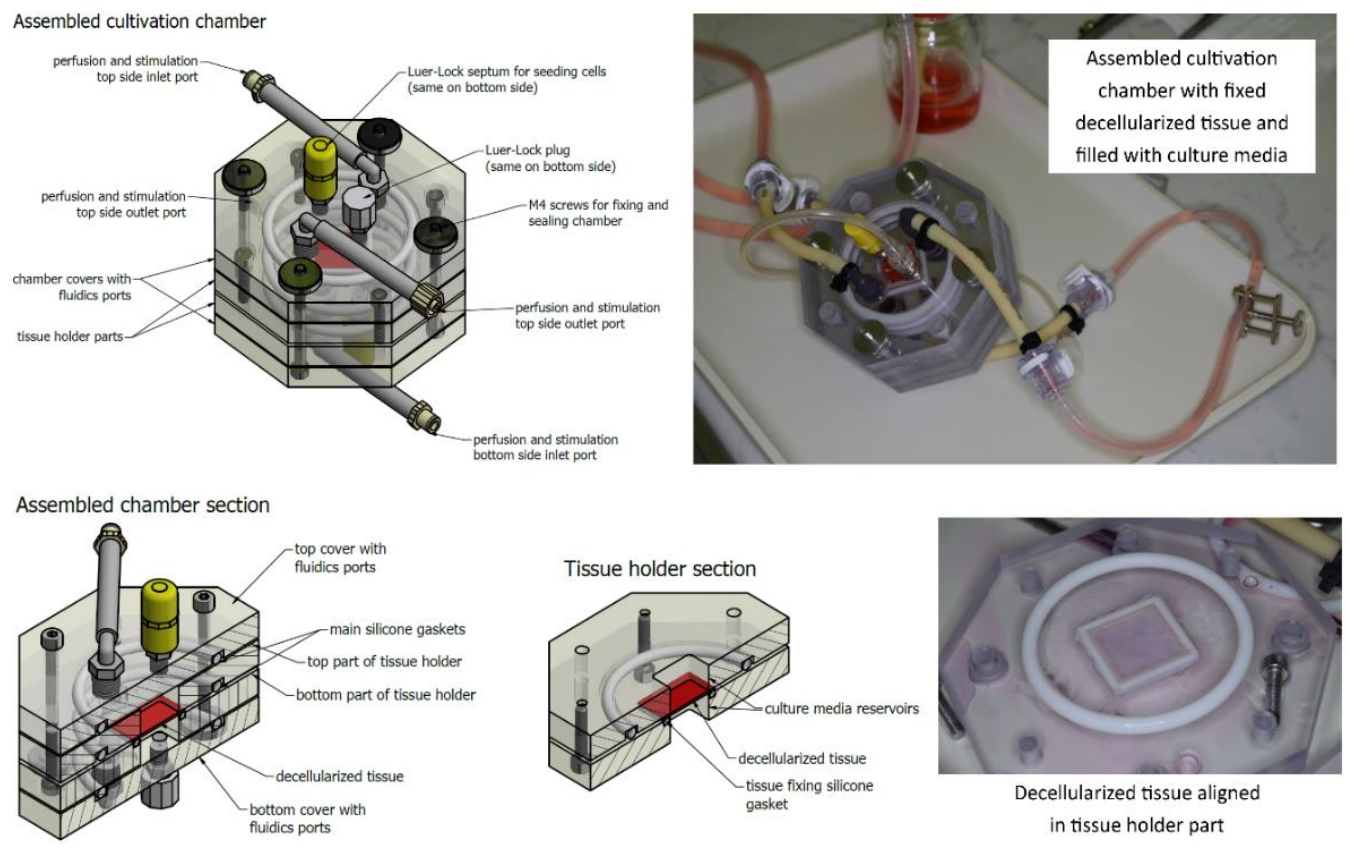

Figure 2. Overall schematic view of the cultivation chamber with sections of the main parts (left). Fully assembled cultivation chamber connected to the perfusion/stimulation system filled with cultivation media (right-top). Detail of a decellularized tissue in the tissue holder part (right bottom).

In order to maintain the perfusion of the tissue with cultivation media and to establish the stimulation of cells with pulsatile pressure waves, a unique system was also developed. This system is based on an electronically controlled linear actuator with the syringe and perfusion circuit connecting. The NI compactDAQ (National Instruments, Austin, TX, USA) platform was used with modules consisting of the digital input/output lines necessary for controlling the pump and valves (module cDAQ 9401), and with an analogue module for the pressure transducer (module cDAQ 9218). Custom LabVIEW (National Instruments, Austin, TX, USA) software was created to control the system. This software controls the movement of the linear actuator and implements a feedback control for the pressure stimulation. This linear actuator with electronics and the control software is depicted in Figure 3. The design of the perfusion system is described in detail in our utility model [25]. The perfusion circuit consists of a silicone tubing, a $20 \mathrm{~mL}$ syringe installed in the linear actuator, and a working reservoir for culture media. The perfusion/stimulation system in this study was optimized to operate in three modes. The modes of operation and the overall setup are illustrated in Figure 4 . In mode 1, perfusion of the cultivation media through the chamber, and in mode 2, refiling the syringe with cultivation media from the reservoir, the system moves at a constant speed until reaching the limit switch on the appropriate side of the movement. These modes were primarily used during the initial 
phase of experiments to equilibrate the $\mathrm{pH}$ and temperature of the cultivation media and to remove all bubbles from the cultivation chamber. Mode 3, pressure stimulation, uses feedback control. In the software, the frequency and two pressure thresholds are specified. Based on these settings, the actuator moves in both directions repeatedly until reaching high/low-pressure thresholds. The speed is adjusted to reach a specified frequency of pulses. The pressure measurement is done with a disposable pressure transducer used for measuring invasive blood pressure TruWave(Baxter, Irvine, CA, USA), which is connected to an auxiliary Luer-Lock in the cultivation chamber.
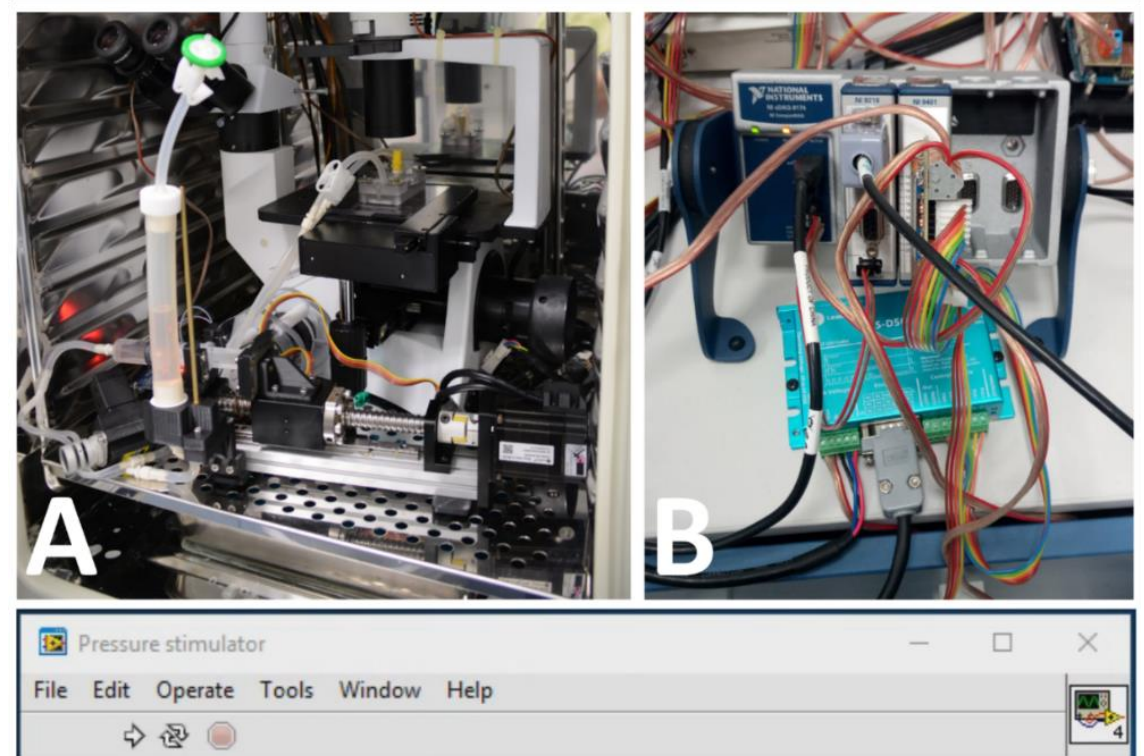

\section{Pressure stimulator control console}

Manual control

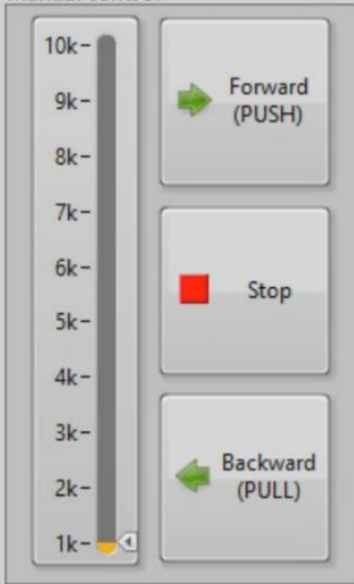

App control

App cont

Exit

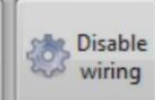

Pressure measurement

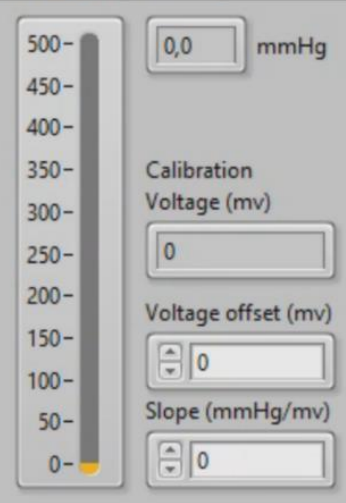

Bypass valve control

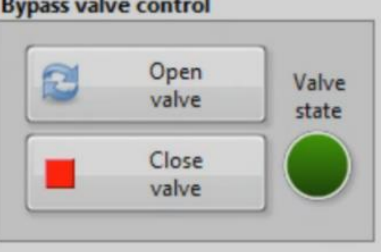

Pressure stimulation

High pressure

in 0

Reach high

Low pressure

A 0

- Reach low pressure

Recirculate

$\mathrm{CO} 2$

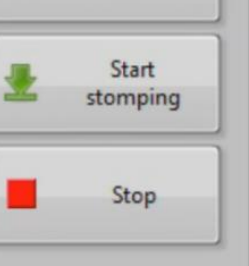

Compact DAQ setup

- vinear stage

DAQ device

$1 / 0$

Pressure

DAQ device

Figure 3. (A) The linear actuator with an installed syringe and working reservoir in a $\mathrm{CO}_{2}$ cell incubator; (B) the compactDAQ control system; (C) the pressure stimulator controlling software GUI. 


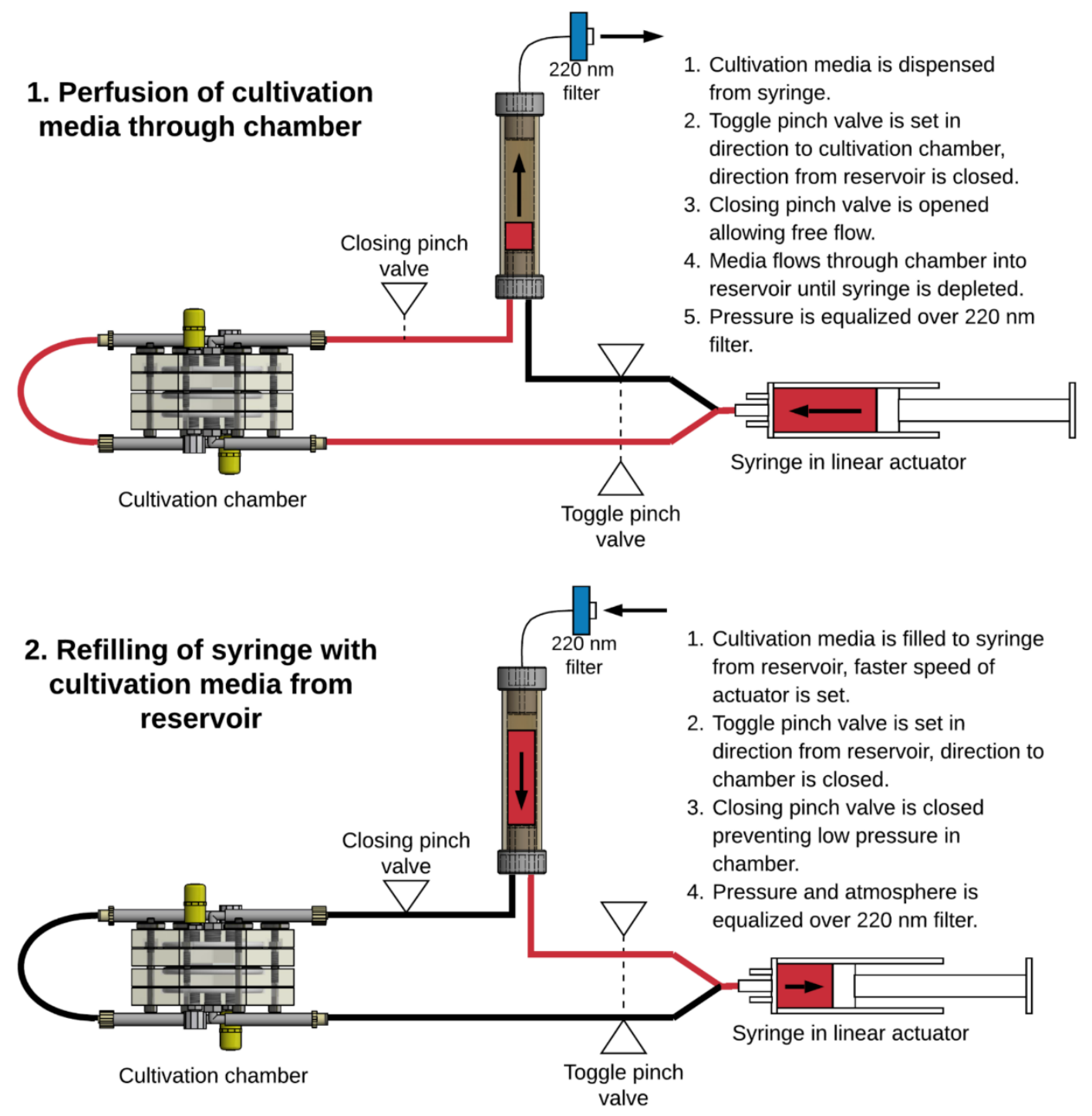

\section{Pressure stimulation with pulsating pressure (hydrostatic)}

\section{Refilling of syringe with reservoir}

\section{(hydrostatic)}

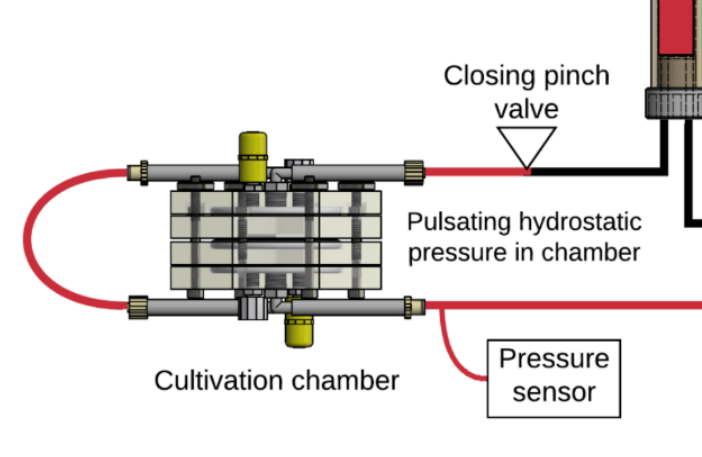

1. Closing pinch valve is closed preventing flow to reservoir.

2. Toggle pinch valve is set in direction to cultivation chamber, direction from reservoir is closed

3. Syringe in actuator is moving in both directions creating pulsatile pressure. Controlling of actuator and its movement is based on actual pressure in chamber measured with pressure sensor.

Syringe in linear actuator

Figure 4. Schematic setup of the perfusion/stimulation circuit with a connected chamber. Three modes of operation used in the cultivation process are shown. 


\subsection{Cell Seeding and Dynamic Cultivation}

Before the cells were seeded, the $\mathrm{pH}$ and the temperature in the cultivation system and in the chamber were equilibrated. In this phase, the culture medium was perfused through the cultivation chamber. All bubbles were also removed. This phase took about $2 \mathrm{~h}$.

Then the cell suspension was prepared. The cells were seeded at a density of $90,000 \mathrm{cells} / \mathrm{cm}^{2}$. This density was experimentally adjusted to form a homogeneous, confluent layer on the top of the decellularized tissue. As was mentioned above, $35 \times 35 \mathrm{~mm}^{2}$ squares of the tissue were fixed in the chamber. The total area for cell growth was $30 \times 30 \mathrm{~mm}^{2}$; the borders were used for fixing the tissue in the holder. Thus, there were 810,000 cells on one side of the tissue, which were suspended in $500 \mu \mathrm{L}$ of the culture medium. This cell suspension was then injected through a sterile septum into the appropriate side of the cultivation chamber. Then, the chamber was aligned horizontally, allowing the cells to adhere. During this phase, there was no perfusion and no dynamic stimulation. The cell adhesion phase took $60 \mathrm{~min}$. After that, mild perfusion (flow $2 \mathrm{~mL} / \mathrm{min}$ ) with the culture medium was started. The perfusion lasted for $2 \mathrm{~h}$. After that, the stimulation was set to $15.9 / 10.6 \mathrm{kPa}(120 / 80 \mathrm{mmHg})$ high/low pressure with a frequency of $1 \mathrm{~Hz}$ ( 60 pulses per minute). Every $2 \mathrm{~h}$, the stimulation was changed to the perfusion mode for $10 \mathrm{~min}$ in order to refill the reservoirs of the chamber with a fresh culture medium. This cultivation was performed for 5 days and for 10 days.

The first goal of this study was to test how well the bioreactor promotes the ingrowth of the cells through the decellularized tissue, so only one side of the tissue was seeded with cells and analyzed. The second goal was to prepare fully recellularized cardiovascular patches. When these patches were being prepared, the cells were seeded from both sides. This procedure involved the described seeding on one side. Then, the cells were left for $60 \mathrm{~min}$, allowing their adhesion. After this phase, the chamber was turned and then the same seeding procedure, but from the second side, was performed, also followed by $60 \mathrm{~min}$ of cell adhesion.

The cultivation medium consists of DMEM/F12 with a 1:1 mixture, supplemented by $10 \%$ of fetal bovine serum, $50 \mu \mathrm{g} / \mathrm{mL}$ of ascorbic acid, $2.5 \mathrm{ng} / \mathrm{mL}$ of TGF- $\beta$ (Transformation growth factor $\beta$ ), $2.5 \mathrm{ng} / \mathrm{mL}$ of BMP4 (Bone morphological protein 4), and 1\% of ABAM antibiotics. This composition was set on the basis of our previous study [17], in order to promote both the growth and the differentiation of the ASCs towards smooth muscle cells. This culture medium was replaced every two days. During replacement, the cultivation chamber and the perfusion circuit were still fully flooded, and only the remaining medium was refilled into a syringe from the working reservoir. Then, the syringe was replaced by a new syringe containing fresh culture medium. These syringe replacements were carried out in a biohazard box to ensure sterility.

A comparative control under static cultivation conditions was performed. In order to ensure the homogeneity of the experimental setup, the second cultivation system with cultivation chambers was used. The preparation included the same preparation steps as above, until the beginning of the $2 \mathrm{~mL} / \mathrm{min}$ perfusion. Instead of perfusion followed by mechanical stimulation, the system with chambers was disassembled, and the tissues were inserted into standard six-well plates. The same culture medium was used and was replaced every two days.

\subsection{Evaluation of Cell Ingrowing}

After observed cultivation intervals (5 and 10 days), the chambers were disconnected from the perfusion/stimulation. The chambers were then disassembled, and the tissues were removed. After that, the tissues were fixed using $4 \%$ paraformaldehyde (PFA) and were washed with PBS. Then, $20 \mu \mathrm{m}$ thick cryosections were made on SuperFrost Pluss glass (ThermoFisher, MA, USA). The cell membranes were then permeabilized using $0.1 \%$ Triton X-100 in PBS for $15 \mathrm{~min}$ at room temperature (RT). The cell nuclei were counterstained with DAPI and mounted with Fluoroshield mounting medium (Sigma-Aldrich, MO, USA).

To quantify the overall cell ingrowth into the decellularized tissue, the images were sliced into $50 \mu \mathrm{m}$ thick layers. The borders of the first layer were set from the surface of the decellularized tissue, 
where the cells were seeded. Then, based on the scale of the image, $50 \mu$ m layers were formed. In these layers, the cell nuclei were counted to quantify the cell ingrowth. This approach is illustrated for analysis in Figure 5. Image processing and analysis were done in ImageJ (National Institutes of Health, Bethesda, Md, USA) and MATLAB (MathWorks, Natic, MA, USA).

\section{Combined brightfield with DAPI}

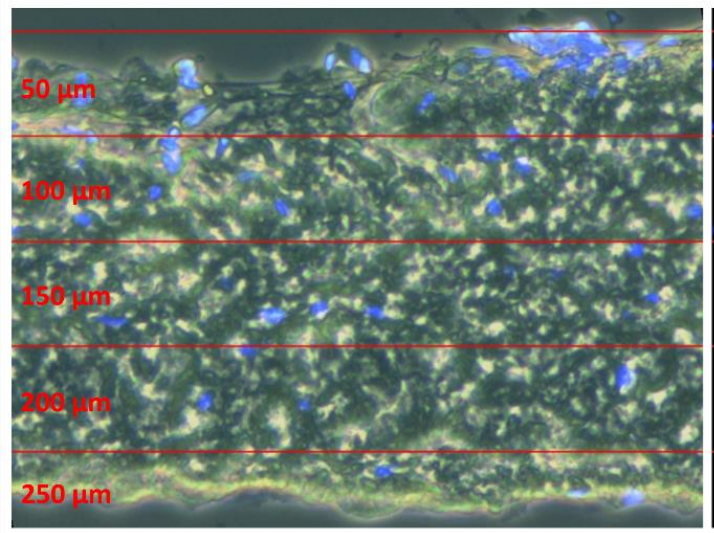

DAPI only

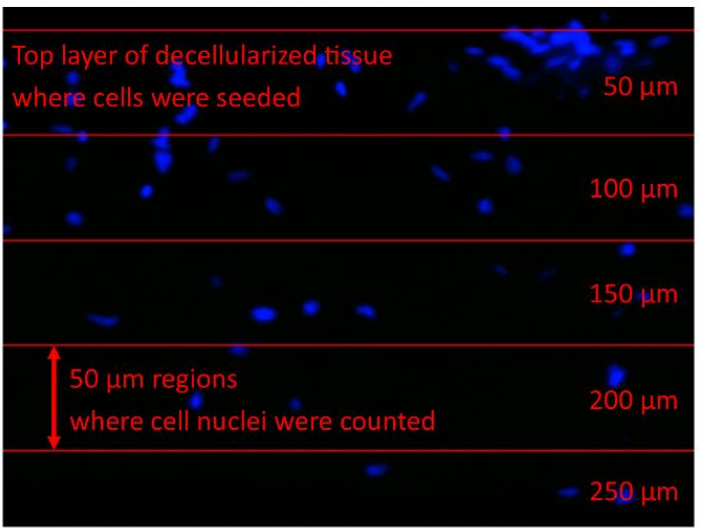

Figure 5. Example of slicing an image into $50 \mu \mathrm{m}$ regions used for cell counting. The original images have been cropped to maintain the same area for analyzing multiple samples.

To obtain relevant results, five random sections for each type of cultivation were analyzed in five randomly selected microscopic fields used for cell counting. The statistical significance was evaluated using nonparametric Kruskal-Wallis One Way Analysis of Variance on Ranks, Dunn's Method, statistical significance $(p \leq 0.05)$ in MATLAB.

Immunofluorescence staining of h1-calponin, considered in various studies as an early marker or as an intermediate marker of SMC differentiation [18], was used for evaluating the differentiation of ASCs towards SMCs. The calponin-h1 Monoclonal Antibody (CALP, MA5-11620, concentration $2 \mu \mathrm{g} / \mathrm{mL}$, ThermoFisher, MA, USA), was applied as the primary antibody. The primary antibody was applied at RT for 120 min to samples in humidified chambers.

Alexa Fluor $488^{\circledR}$-conjugated $\mathrm{F}\left(\mathrm{ab}^{\prime}\right)$ fragment of goat anti-mouse IgG (H1L, Cat. No. A11017, Sigma-Aldrich; diluted in PBS + 1\% BSA, concentration $1 \mu \mathrm{g} / \mathrm{mL}$ ), together with Phalloidin conjugated with TRITC (P1951, Sigma-Aldrich; concentration $2 \mu \mathrm{g} / \mathrm{mL}$ ), was applied as the secondary antibody, after the mouse monoclonal primary antibody. The cell nuclei were counterstained with DAPI (Thermo-Fisher, MA, USA; D1306, 300 nM concentration), which was added together with the secondary antibody. The samples were incubated with the secondary antibody at RT for $60 \mathrm{~min}$ in humidified chambers. Microscopic images were taken using Carl Zeiss LSM 880 NLO confocal microscope and Leica DMi-8 fluorescence microscope.

\section{Results}

\subsection{Decellularized Porcine and Ovine Pericardium Used for Autologous Recellularization}

Several steps were done to check that the tissue had been decellularized properly for use as scaffolds for further recellularization and in vivo implantation. After the decellularization process and the sterilization had been completed, the tissue was histologically analyzed. As can be seen in Figure 6, the native tissue has visible cell nuclei. This sample was taken as a control. After SDS treatment, the cells were lysed, as a result of which DNA was spilt over the tissue. The DNA residues had to be removed in order to minimize any immune response; enzymatic treatment of the tissue was therefore carried out. After this treatment and a washing step, there were no visible residues of the original cells or of the DNA. Secondly, cytotoxicity tests on the decellularized tissues were performed. These tests included cell cultivation in leachates from the decellularized tissues, and also direct seeding of cells on 
and near the tissues inserted in the well plates. Both methods revealed normal cell growth, which was the same as in the control cells grown without the decellularized tissue or the leachate, indicating no cytotoxicity of the decellularized matrices. In addition, the bacterial tests according to Ph. eur. 2.6.1 and ČSN EN ISO 11737-2 analysis provided negative results, which verified that sterilization using a $70 \%$ ethanol solution was sufficient. Following cell cultivation also demonstrated that the tissue decellularized by the method described here is suitable for recolonization with cells as can be seen later in this study.

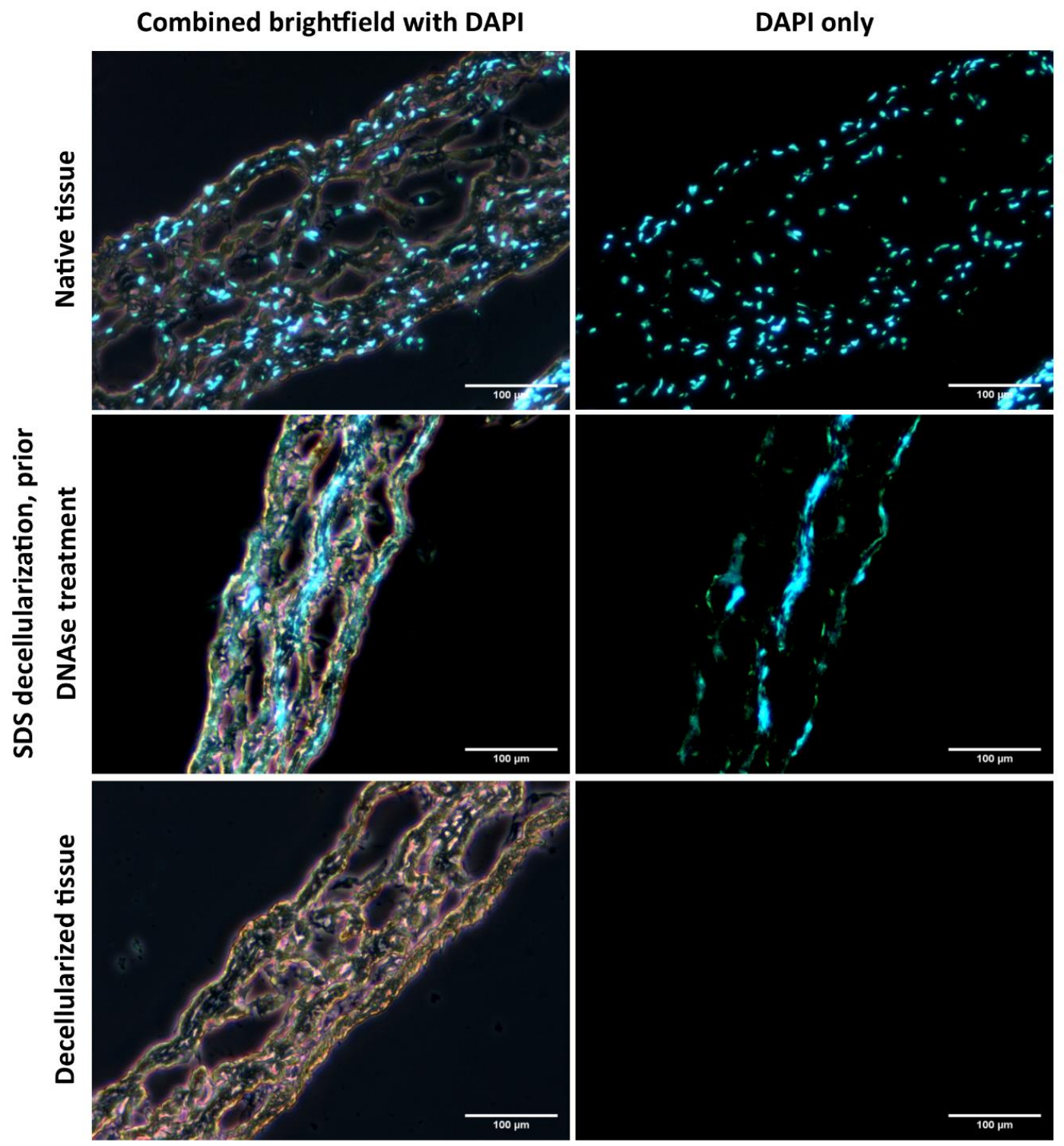

Figure 6. Evaluation of the decellularization process using cryosections $10 \mu \mathrm{m}$ in thickness stained with DAPI. The brightfield images and the fluorescence images were combined to visualize both the tissue and the remaining nuclei/DNA. From top to bottom: A sample of native tissue with visible cell nuclei. The tissue after SDS cycles, where no cell nuclei are visible, but the residual DNA is spilt over the tissue. A completely decellularized tissue with no remaining visible cells or DNA residues. The Leica DMi 8 microscope, 10x objective, and scale bar $100 \mu \mathrm{m}$ were used.

\subsection{Ingrowing of Stromal Cells Into Decellularized Tissue and Its Differentiation Towards SMCs}

An analysis of the histological images (demonstrated in Figure 7) and the cell numbers at given depths (demonstrated in Figure 8) shows a fundamental difference between static cultivation and 
dynamic cultivation. In static conditions, there is no significant difference between 5 and 10 days of cultivation. In both cases, the cells penetrated to a depth of $50 \mu \mathrm{m}$, but there is no evidence of cell ingrowth into deeper regions of the tissue.
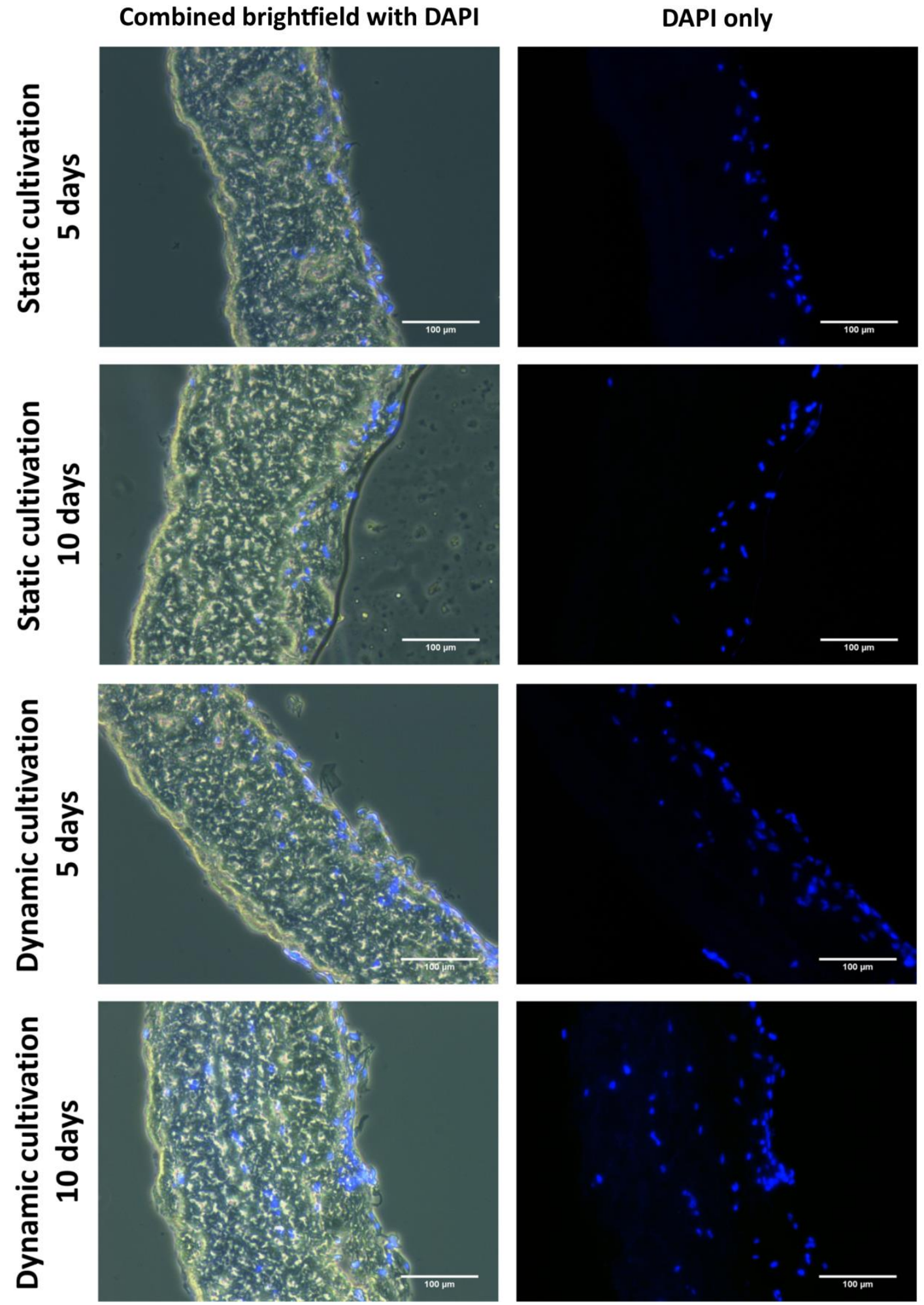

Figure 7. DAPI counterstained cryosections of recellularized tissues cultivated in static and dynamic conditions for 5 days and for 10 days. Tissues prior to cultivation were seeded from a single side of decellularized tissue. The microscope used Leica DMi 8, 10× objective. 
However, the results for dynamic cultivation show improved penetration of the cells into all layers of the tissue, with some decreasing character where the number of cells decreases with depth. At depths $>100 \mu \mathrm{m}$, there is a significant difference between static cultivation and dynamic cultivation. In both time intervals, there are observable cells in all layers of the dynamically-cultivated samples. After 10 days of dynamic cultivation, it can be seen that almost all the tissue has been newly recellularized with cells.

\section{Number of cells in given depths of tissue}

(comparison of static and dynamic conditions and two time intervals)
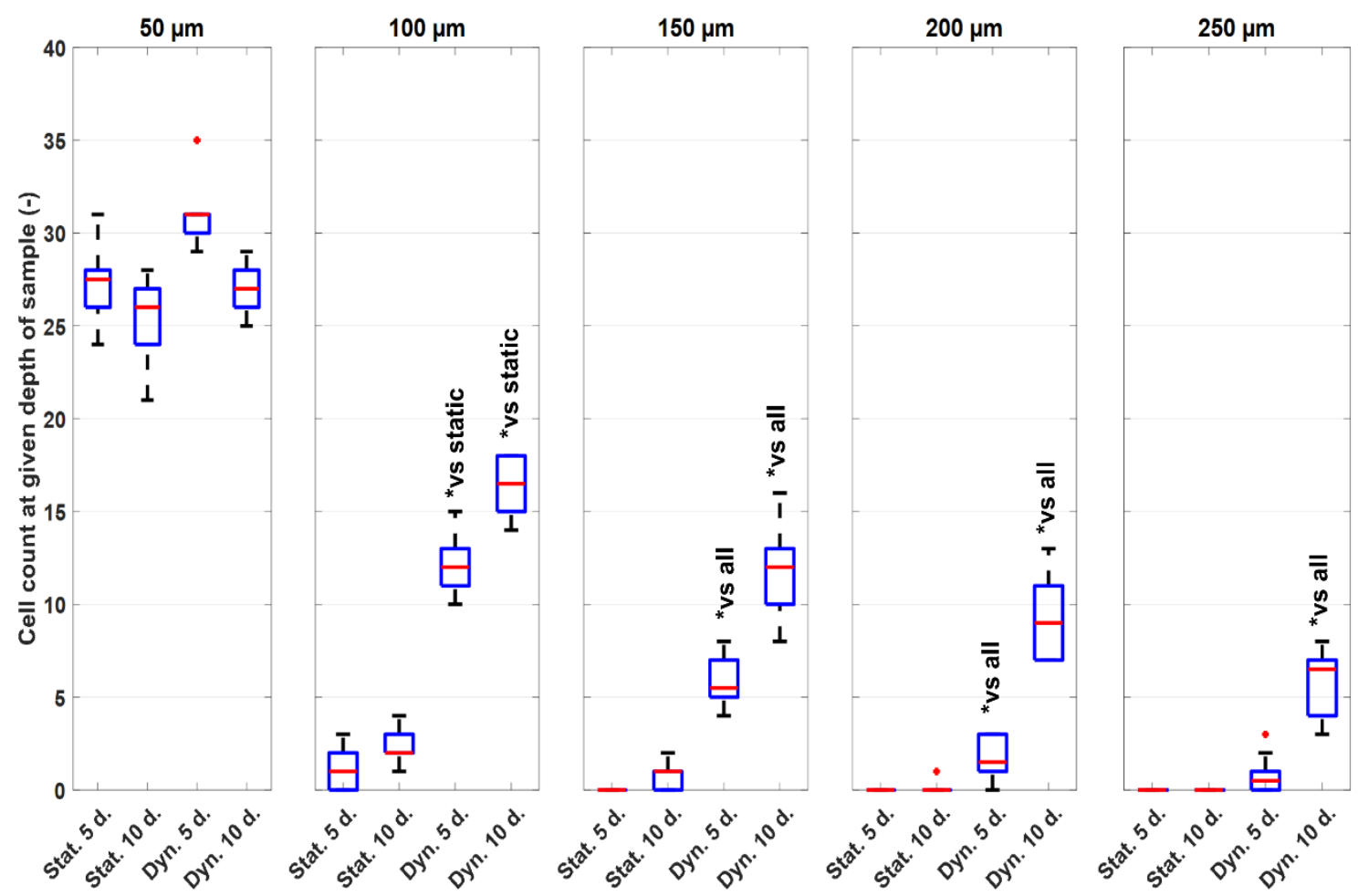

Figure 8. The number of cells in given depths of tissue in static and dynamic conditions with single side seeding. Statistical significance is for $p<0.05$. Ten samples were taken for every type of cultivation and time interval. Each of the samples was sliced to $50 \mu \mathrm{m}$ depth regions where cell numbers were counted. Red lines represent the median values; blue boxes 1st and 3rd quartiles; whiskers are the minimum and maximum; and the red circles are outliers.

An analysis of the growth and differentiation of cells on the surface of the decellularized matrix showed that there is a major difference between static cultivation and dynamic cultivation after 10 days of cultivation. As shown in Figure 9, under static conditions, the cells form clusters instead of spreading homogeneously over the entire surface. The signal from h1-calponin is also weaker and is present in a smaller number of cells. Under dynamic conditions, however, a homogeneous cell layer is formed, and h1-calponin is present in most of the cells, including cells with well-developed calponin fibres. In this case, increased cell growth and overall improved growth of cells on the surface of decellularized tissue can also be observed under dynamic culture conditions. 


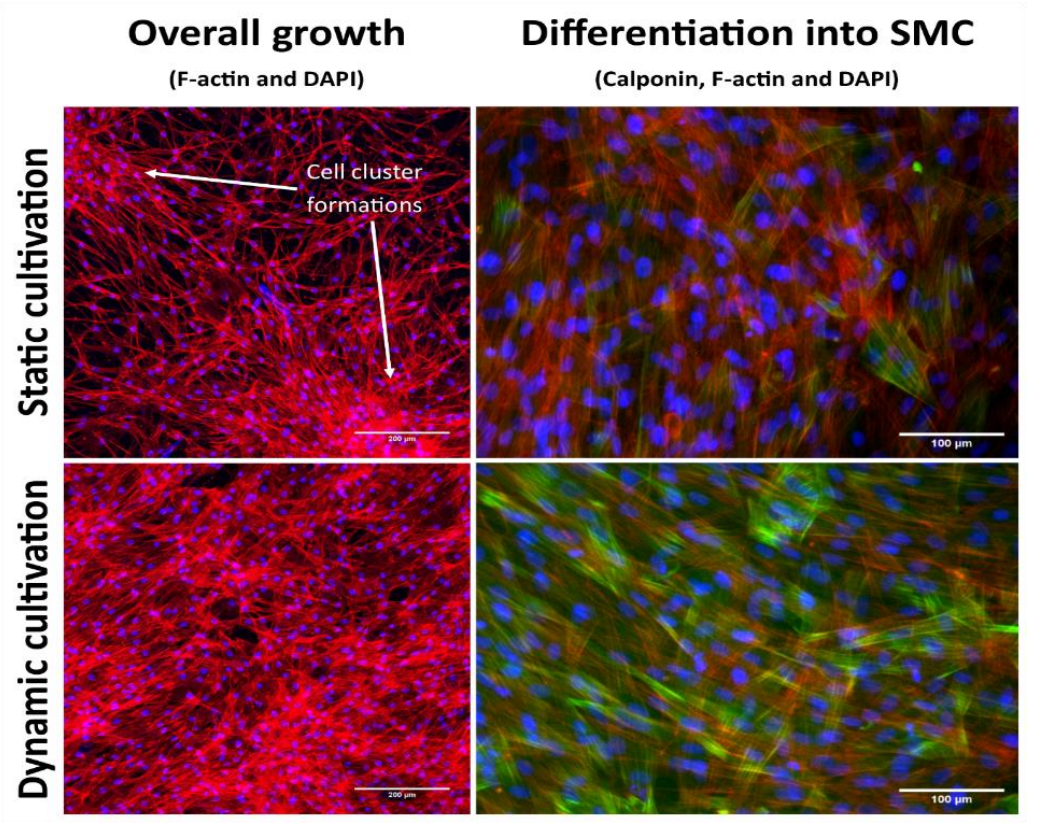

Figure 9. Immunofluorescence staining of the cultivated decellularized pericardium (red-F-actin, green-H1-calponin, blue-DAPI) in static and dynamic conditions for 10 days. For overall growth images, a Carl Zeiss 880 NLO confocal microscope was used with 10x objective and extended field of view. For differentiation images, a Leica DMi8 with 20x objective was used.

\subsection{Preparation of Recellularized Cardiovascular Patches}

As was mentioned in the Material and Methods section of this study, we tried to demonstrate the efficiency of dynamic cultivation in stimulating cell ingrowth inside the decellularized tissue. For this experiment, only one side of the pericardium was seeded with cells, and the depth of the cell penetration into the tissue was evaluated. As described above, cells were penetrating nearly the whole tissue after 10 days of dynamic cultivation. However, the density was decreasing with depth. After 5 days of dynamic cultivation, cells were able to penetrate at half of the depth of the decellularized tissue.

To achieve more homogeneous cell colonization for preparing implantable cardiovascular patches, both sides of the decellularized tissue were seeded with cells prior to pressure stimulation. The design of the cultivation chamber was also optimized when the two covers of the chamber implemented Luer-Locks (LLs) in order to use a sterile septum for cell seeding. In this case, ovine decellularized pericardium was also used. The protocol for the ovine pericardium was the same as for the porcine tissue, except that the tissue was sourced from experimental sheep. We had only a limited amount of pericardial tissue because we had access to just a small number of sheep that had originally been used for other studies. The overall method for testing and validation was, therefore, based on the porcine pericardium. However, in further studies, ovine pericardium will be used for implantation into pigs in order to simulate a xenogeneic tissue that will be repopulated with autologous porcine cells.

Also, the total dynamic cultivation time was reduced to 5 days when both sides of tissue were seeded prior to dynamic cultivation. This method offers a considerable advantage when preparing autologous cell-seeded grafts due to the reduced time needed for recellularizing the decellularized tissue. The difference between single-side and both-sides seeding after 5 days of dynamic cultivation is illustrated in Figure 10.

As is demonstrated in Figures 11 and 12 on $20 \mu \mathrm{m}$ paraffin-embedded sections stained with hematoxylin and eosin HE and DAPI, the PrASCs were homogeneously distributed inside the recellularized porcine tissue samples and ovine tissue samples. There was no difference between the ovine and porcine tissues in terms of cell colonization. 


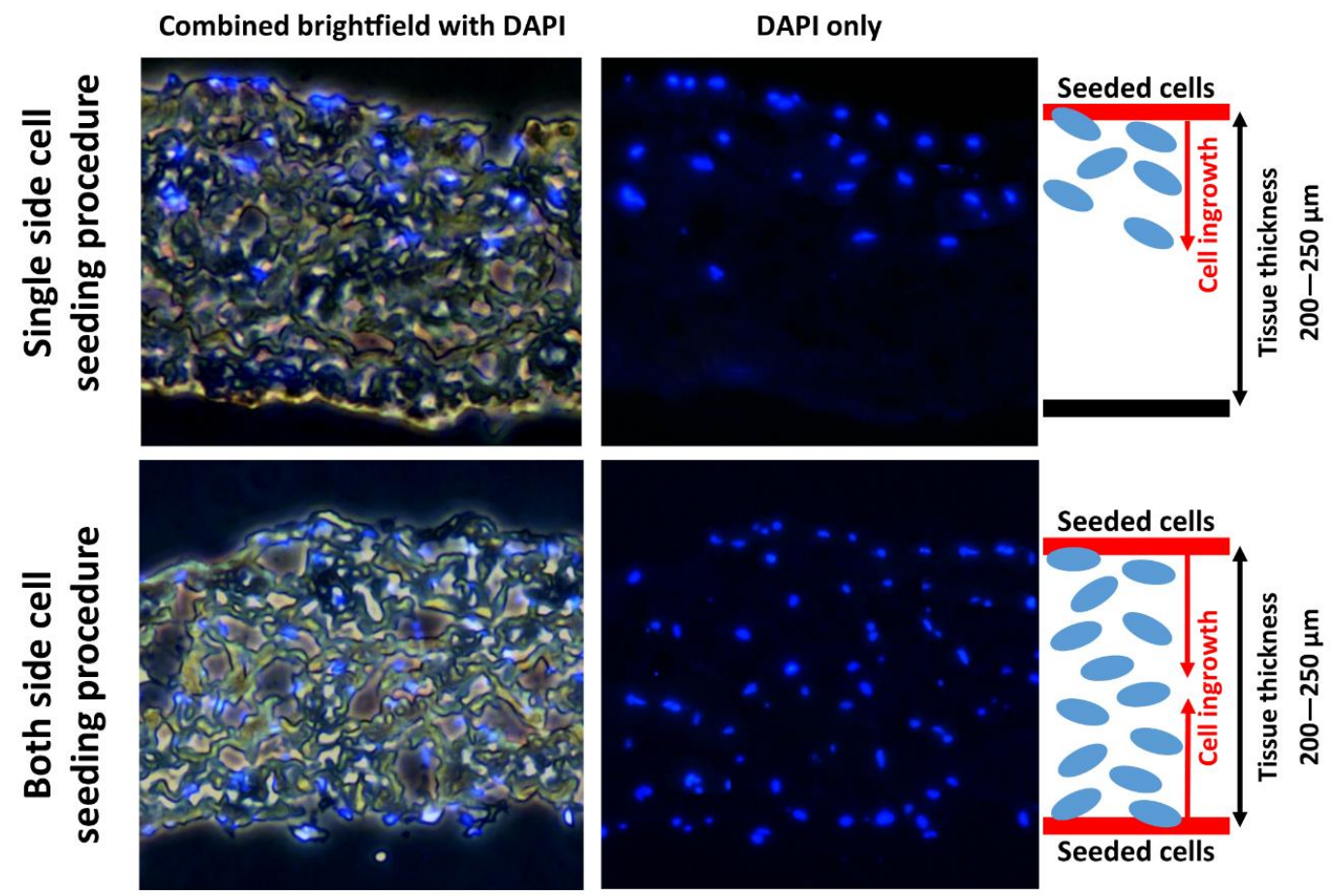

Figure 10. Comparison between single- and both-sides cell seeding procedures. The cultivation time in both procedures was 5 days in dynamic conditions.

\section{Recellularized porcine pericardium}
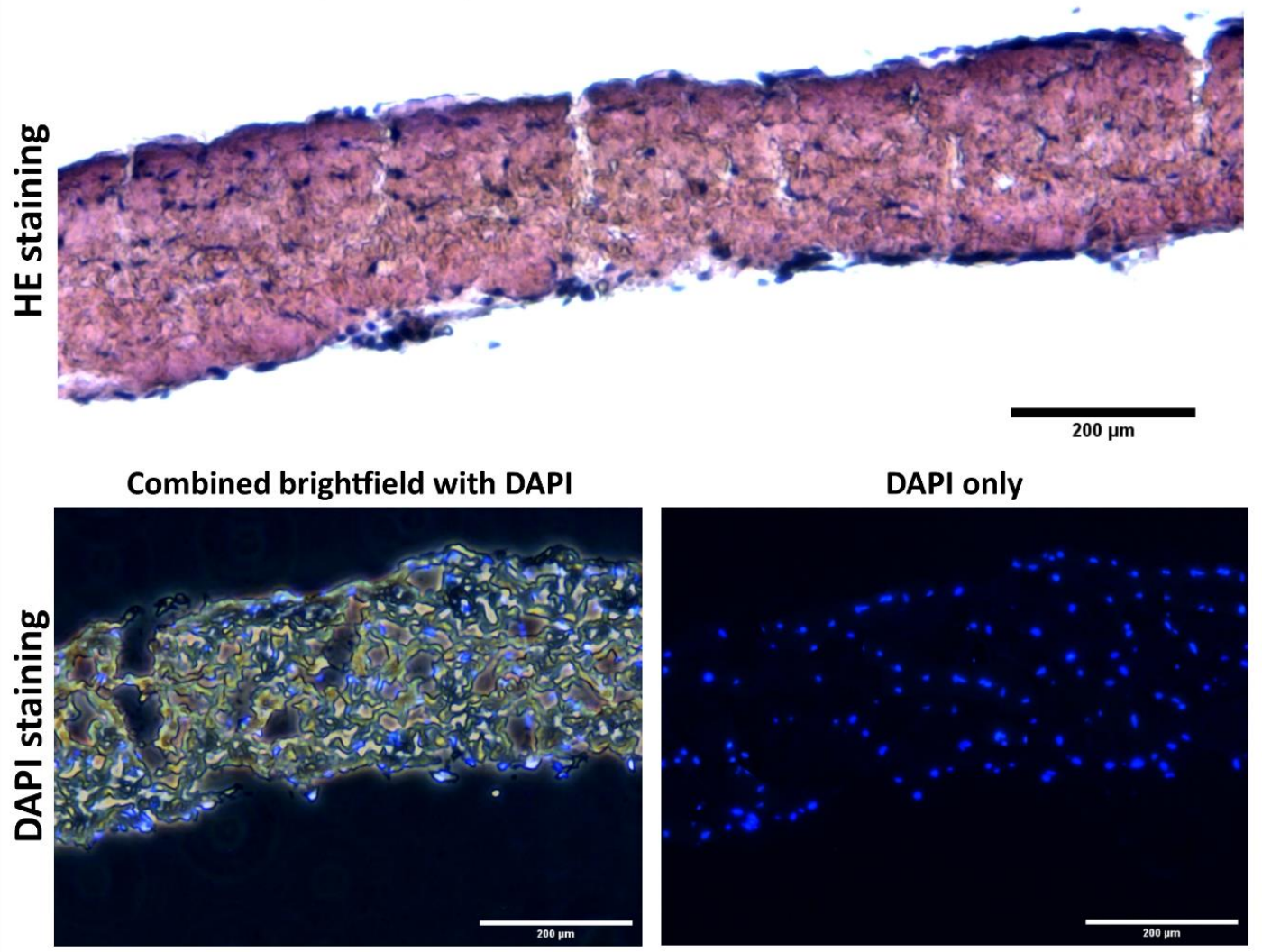

Figure 11. Paraffin-embedded $20 \mu \mathrm{m}$ sections of porcine recellularized pericardium stained with hematoxylin-eosin (HE) and DAPI. Cells were seeded from both sides of the decellularized tissue prior to dynamic stimulation. Cultivation was held for 5 days in a dynamic culture system. 


\section{Recellularized ovine pericardium}
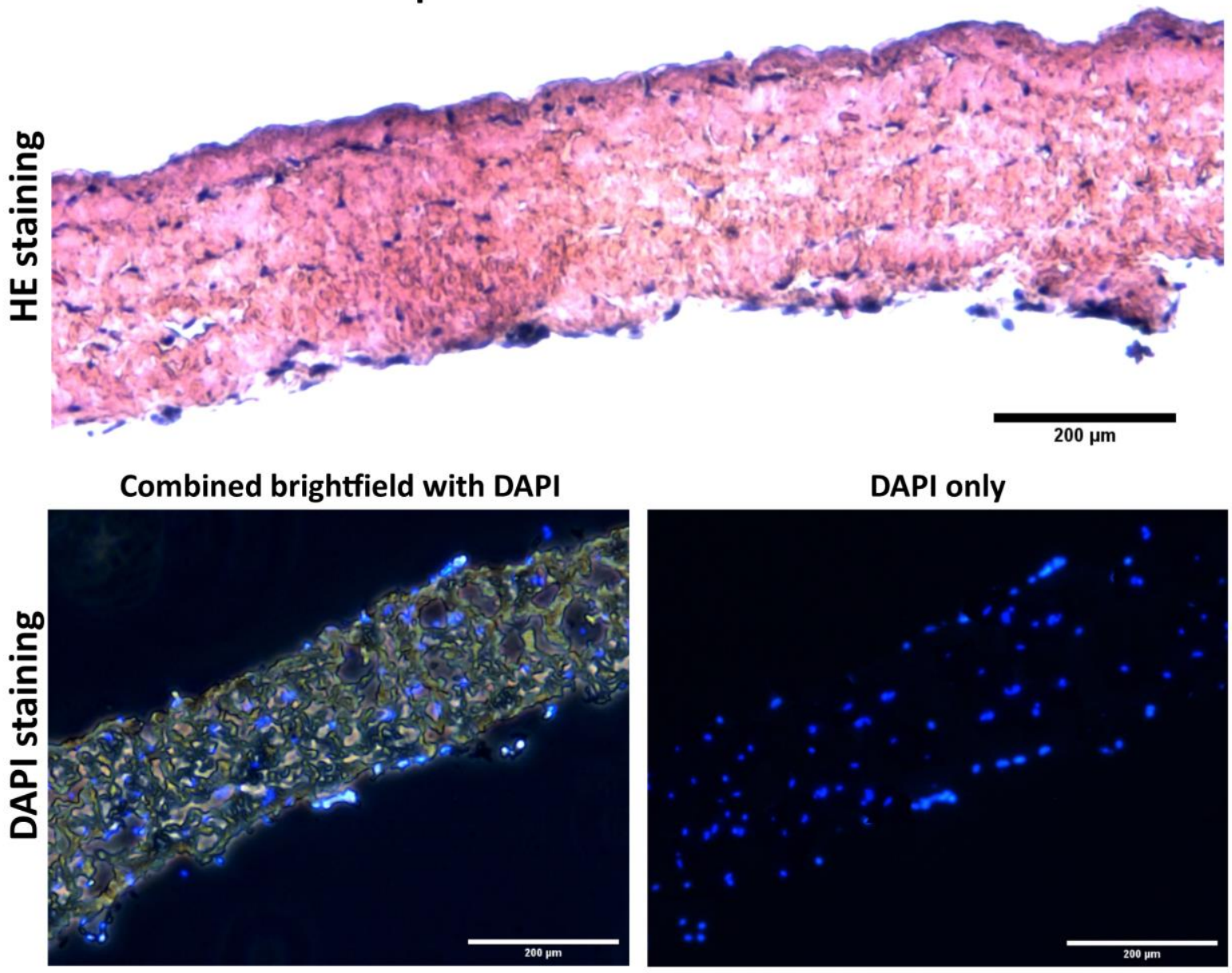

Figure 12. Paraffin-embedded $20 \mu \mathrm{m}$ sections of ovine recellularized pericardium stained with hematoxylin-eosin (HE) and DAPI. Cells were seeded from both sides of the decellularized tissue prior to dynamic stimulation. Cultivation was held for 5 days in a dynamic culture system.

\section{Discussion}

The operating protocol involving the decellularization agents, such as SDS, DNAse, and deionized water, was adopted and modified according to the studies by Crapo et al. and by Gilbert et al. [10,11]. Many of the methods described require repeated steps involving changing decellularization agents or water after a certain period to maintain a chemical concentration gradient. Also, to improve the method and ensure homogenous decellularization, agitation in a shaker is used. These steps can be time-consuming. To ease these steps and ensure uninterrupted automation of the overall process, a novel system was built. This system implements a cyclic-based process of changing agents and washing water based on the desired setting. This approach alters the manual changing of them. Also, a special cultivation chamber was used where the tissue is fixed, and the chamber allows the flowing of used liquids to flow over the tissue, improving homogeneity.

As demonstrated in Figure 6, the native tissue has visible cell nuclei, whereas in the fully decellularized tissues there were no visible cell nuclei or DNA residues. The cell cultivation, both in the dynamic cultivation system and in static conditions, also demonstrated that the tissue decellularized by the method described here is suitable for recolonization with cells. The cells adhering to the surface of the decellularized tissue were able to penetrate the tissue. However, under static conditions, the cells formed clusters instead of a homogeneous spread on the surface of the tissue when observed under dynamic conditions, as illustrated in Figure 9. 
It can, therefore, be summarized that this protocol, implemented into our decellularization system, provided a decellularized porcine pericardium matrix that is non-toxic, sterile, and ready for further recellularization and use as an experimental cardiovascular patch. The whole process can be completed within $24 \mathrm{~h}$. The decellularization chamber designed for fixing the planar tissue can prepare tissues up to $12 \times 8 \mathrm{~cm}^{2}$ in size in a single run. As was mentioned above, the porcine pericardium was harvested from a local slaughterhouse and was a cheap and easily obtainable source of tissue for validating the method. The ovine pericardium was also decellularized and was further tested to form a xenogeneic substrate with autologous cells (PrASCs) for further implantation into a porcine in vivo model to verify low immunogenicity of decellularized matrices reported in the literature $[8,9,26]$.

Cell seeding is an important component of vascular tissue engineering that decreases graft thrombogenicity and promotes graft patency, regardless of the cell type used. A possible mechanism is the recruitment of autologous cells in a paracrine manner and accelerated regeneration of the seeded matrices into a neovessel. A method of static seeding passively introduces cells onto a scaffold. The cell maturation and penetration into the scaffold is low.

As has been described above, the process of recellularization in static conditions does not give satisfactory results. As is illustrated in Figures 7 and 8, only 1/5 $(50 \mu \mathrm{m})$ of the decellularized tissue was penetrated with cells after 10 days of static cultivation. Similar results have also been obtained in other studies, in which several weeks of cultivation were needed to overgrow various matrices with cells and to achieve cell maturation [15]. The speed of the overall recellularization process is increased when perfusion bioreactors are used to provide mechanical stimulation of the cells according to studies by Melchiorri et al. [27]. Also, many studies have investigated the correlation between pressure strain, cell proliferation, and stem cell differentiation towards SMCs. Cyclic physiological pressure (CP) of 120/80 torr altered the cellular morphology and increased the proliferation rates in stem cells over a 7-day period as described in the study by Maul et al. [28]. Moreover, dynamic seeding using a bioreactor enables preconditioning of the cells under more physiological conditions, as described in the study by Villalona et al. [15].

A custom dynamic cultivation system built in our laboratory was used in this study. This system generates a microperfusion flow and pulsatile hydrostatic pressure. As mentioned above, in static conditions, the cells penetrated only in $50 \mu \mathrm{m}$ depth. The tissues cultivated in dynamic conditions proved significantly better penetration rates of cells. Significant results are observable from $100 \mu \mathrm{m}$ depths. At depths $>150 \mu \mathrm{m}$ and more, there is nearly no evidence of cells ingrowing in static conditions. As is illustrated in Figures 7 and 8 after 10 days of dynamic cultivation, most of the tissue has been newly recellularized with cells. As was mentioned, we tried to demonstrate the efficiency of a dynamic cultivation bioreactor in stimulating cell ingrowth inside the decellularized tissue. So, the technique of seeding utilized only one side of the decellularized tissue. Thus, the number of cells decreased with the penetration depth. To promote more homogenous ingrowing of cells, the cultivation chamber was optimized for dual side seeding of cells. In this approach, both sides of decellularized tissues were seeded with the same density of cells prior to cultivation. As is illustrated in Figures 11 and 12, the cells are homogeneously distributed inside the recellularized tissue. Also, the time period used to achieve this was reduced to 5 days.

Also, the differentiation of ASCs towards the SMC phenotype can be achieved via biochemical and mechanical stimulation. A positive effect on the differentiation of stem cells towards SMCs has been demonstrated in studies using a combination of TGF- $B$ and BMP4 growth factors. This led to an increase in the production of specific cytoskeletal protein markers of differentiation, such as $\alpha$-actin and h1-calponin, which are present only in differentiated SMCs [29], after 7 and more days of static cultivation. Cell differentiation towards the SMC phenotype can be further enhanced by appropriate mechanical stimulation in a dynamic cell culture system. The positive effect of mechanical stimulation on differentiation towards SMCs has been described for cells cultured either with or without the presence of TGF- $B$ and BMP4 $[17,30]$. In addition, mechanical stimulation helps to keep the cells in a differentiated state and prevents de-differentiation [31]. 
As for mechanical stimulation, we applied physiological hemodynamic force, which is stimulation with cyclic hydrostatic pressure (CP) $120 / 80 \mathrm{mmHg}$. The CP induced differentiation of the seeded adipose-derived stromal cells towards the SMC phenotype. This was proven by the expression of an SMC marker calponin. Greater cell population density and greater upregulation of early differentiation markers $\alpha$-actin and calponin were achieved in a pressure-stimulated culture than in static conditions [18,32]. In this context, two mechanosensitive signaling pathways associated with SMC differentiation have been described: the RhoA-associated pathway, and the FAK kinase-associated pathway. Activation of these signaling pathways leads to increased synthesis of SMC differentiation markers in the cells [33].

An analysis of the growth and differentiation of cells on the surface of the decellularized matrix showed that there is a major difference between static cultivation and dynamic cultivation after 10 days of cultivation. As shown in Figure 9, under static conditions, the cells form clusters instead of spreading homogeneously over the entire surface. The signal from h1-calponin is also weaker and is present in a smaller number of cells. Under dynamic conditions, however, a homogeneous cell layer is formed, and h1-calponin is present in most of the cells, including cells with well-developed calponin fibers. In this case, increased cell growth and overall improved growth of cells on the surface of decellularized tissue can also be observed under dynamic culture conditions.

Analogous to our study, Kobayashi et al. found upregulated expression of SMC markers, alpha smooth muscle actin (aSMA), and smooth muscle myosin heavy chain (SMMHC) in rat bone marrow stromal cells after exposure to pressure-dominant forces or combined flow and pressure forces for 3 days [34]. The authors attribute this differentiation to longer pre-incubation periods (7-21 days). The effects of different types of mechanical stimulation in isolation cyclic strain and cyclic pressure, including cyclic pressure alone, were previously studied in detail in rat bone marrow mesenchymal stem cells plated on collagen type-I coated culture slips [28,35]. In contrast to our study, they found no SMC markers (including no calponin) via immunohistochemistry after 5 days of $\mathrm{CP}$ of different magnitudes. Although the cells were increasing in number under CP in the study by Maul et al. [35], in our study, we initially seeded the cells in a much higher density $\left(90,000\right.$ cells $\left./ \mathrm{cm}^{2} \mathrm{vs} .200 \mathrm{cells} / \mathrm{cm}^{2}\right)$ to achieve confluence on a 3D biological material—decellularized pericardium. Our setting most probably resulted in simultaneous signaling from more sources: cell-cell contacts, cell-material contacts (natural matrix environment), soluble factors (TGF- $\beta 1$ and BMP-4), and the mechanical load. These stimuli create synergy in conditioning the cells [36]. This may explain the fact that the cells differentiated towards the intended SMC-phenotype in our system. Additionally, the cells penetrated through the entire wall of the matrix, thus resembling a newly formed vascular tunica media. Cyclic pressure is a known factor that induces the proliferation of several cell types (EC, SMC and MSC) [28,35,37]. We believe that these are desired events with respect to vascular tissue engineering and future implantation of this matrix as a cell-seeded cardiovascular patch.

In a future study, we plan to prepare autologous cell-seeded cardiovascular patches based on the protocol described here. Cultivation substrate will involve both autologous (porcine) Figure 11, and xenogenous (ovine) Figure 12 decellularized tissues as a substrate. In this planned study, the animals (Prestice pigs) will undergo two surgeries-the first surgery for fat tissue extraction and ASC isolation, and the second surgery in which a patch will be implanted onto an experimental carotid artery defect. Based on the protocol presented here, the time needed for preparing the recellularized autologous patch will be approximately 8-10 days for preparing the autologous ASCs and then 5 days of cultivation in the dynamic bioreactor to prepare the recellularized autologous seeded grafts.

\section{Conclusions and Further Perspectives}

In this study, we have prepared decellularized pericardium repopulated with adipose tissue-derived stromal cells for potential use as implantable cardiovascular patches. To achieve this aim, novel optimized dynamic decellularization and recellularization systems, fabricated in our laboratory, have been used and demonstrated in this study. In the decellularization system, the planar 
tissue is exposed on both sides to a continuous flow of the decellularization agents (SDS and DNAse) and the washing medium $\left(\mathrm{dH}_{2} \mathrm{O}\right)$, which are automatically changed. This process, taking approximately 1 day, provided a completely decellularized non-cytotoxic matrix suitable for further recellularization. The recellularization was performed using porcine adipose tissue-derived stromal cells and a unique custom-made dynamic bioreactor generating pulsatile pressure stress. This mechanical stimulation markedly accelerated the penetration of cells inside the decellularized tissue, their proliferation, and particularly their differentiation towards smooth muscle cells, i.e., an important cell type and the most numerous cell type in the vascular wall. While the decellularization and recellularization procedures in conventional static systems usually take several weeks, our newly developed systems need only about two weeks, including decellularization (approx. 1 day), isolation, and expansion of ASCs (8-10 days) and recellularization (5 days). The newly prepared pericardium patches recellularized with pre-differentiated stromal cells are intended for treating an experimentally-induced carotid artery defect in a porcine model in vivo in order to develop novel cardiovascular patches that can be applied in human medicine.

Author Contributions: Conceptualization R.M., M.K., J.C., S.F.; Data curation R.M.; Formal analysis J.̌̌., R.M.; Funding acquisition P.K., L.B., S.F., J.P.; Investigation R.M., M.K, J.C., Š.P., A.B.; Methodology M.K., J.C., R.M., S.F.; Project administration J.P., P.K.; Resources J.L., Z.Š., I.M., D.T.,; Software R.M., J.Š.; Supervision J.P, J.R.; Validation J.Š., Š.P.; Visualization Š.P., R.M.; Writing—original draft R.M., M.K., J.C.; Writing-review \& editing S.F., J.R., L.B. All authors have read and agreed to the published version of the manuscript.

Funding: The research was supported by the Ministry of Health of the Czech Republic grants No. NV18-02-00422 and 15-29153A; by the Ministry of Education, Youth and Sports of CR by the project "BIOCEV" reg. no. CZ.1.05/1.1.00/02.0109. All rights reserved.

Acknowledgments: The authors thank Ivana Zajanova (Institute of Physiology, Czech Academy of Sciences, Prague, Czech Republic) for her assistance with the preparation of thin cryosections of samples; Michal Bures (Institute of Clinical and Experimental Medicine, Prague, Czech Republic) caring for experimental animals and staff of Steinhauser s.r.o. for allowing the porcine pericardium to be extracted. Robin Healey (Czech Technical University, Prague) is gratefully acknowledged for his language revision of the manuscript.

Conflicts of Interest: The authors declare no conflict of interest.

Ethical statement: The animal experiments in this study were approved by the Ministry of Health of the Czech Republic reference no MZDZ 23132/2018-4/OVZ approval no 37/2018 and reference no MZDZ 48434/2015-OVZ-30.0-21.8.15 approval no 58/2015. A minimal number of animals was used. All procedures described were done under general anaesthesia and according to ethical guidelines to minimize the pain and discomfort of animals. The Institute of Clinical and Experimental has authorized facilities and fully equipped operating theatres for performing these animal experiments.

\section{References}

1. Pashneh-Tala, S.; MacNeil, S.; Claeyssens, F. The Tissue-Engineered Vascular Graft-Past, Present, and Future. Tissue Eng. Part B Rev. 2016, 22, 68-100. [CrossRef] [PubMed]

2. Fahner, P.J.; Idu, M.M.; van Gulik, T.M.; Legemate, D.A. Systematic review of preservation methods and clinical outcome of infrainguinal vascular allografts. J. Vasc. Surg. 2006, 44, 518-524. [CrossRef] [PubMed]

3. Chlupác, J.; Filová, E.; Bacáková, L. Blood vessel replacement: 50 years of development and tissue engineering paradigms in vascular surgery. Physiol. Res. 2009, 58 (Suppl. 2), S119-S139.

4. Kumar, V.A.; Brewster, L.P.; Caves, J.M.; Chaikof, E.L. Tissue Engineering of Blood Vessels: Functional Requirements, Progress, and Future Challenges. Cardiovasc. Eng. Technol. 2011, 2, 137-148. [CrossRef] [PubMed]

5. Smit, F.E.; Dohmen, P.M. Cardiovascular tissue engineering: Where we come from and where are we now? Med. Sci. Monit. Basic Res. 2015, 21, 1-3. [CrossRef]

6. Texakalidis, P.; Giannopoulos, S.; Charisis, N.; Giannopoulos, S.; Karasavvidis, T.; Koullias, G.; Jabbour, P. A meta-analysis of randomized trials comparing bovine pericardium and other patch materials for carotid endarterectomy. J. Vasc. Surg. 2018, 68, 1241-1256. [CrossRef]

7. Rodriguez-Gabella, T.; Voisine, P.; Puri, R.; Pibarot, P.; Rodés-Cabau, J. Aortic Bioprosthetic Valve Durability: Incidence, Mechanisms, Predictors, and Management of Surgical and Transcatheter Valve Degeneration. J. Am. Coll. Cardiol. 2017, 70, 1013-1028. [CrossRef] 
8. Abdolghafoorian, H.; Farnia, P.; Nia, R.; Bahrami, A.; Dorudinia, A.; Ghanavi, J. Effect of Heart Valve Decellularization on Xenograft Rejection. Exp. Clin. Transplant. 2016, 15, 329-336.

9. Lin, C.H.; Hsia, K.; Ma, H.; Lee, H.; Lu, J.H. In Vivo Performance of Decellularized Vascular Grafts: A Review Article. Int. J. Mol. Sci. 2018, 19, 2101. [CrossRef]

10. Crapo, P.M.; Gilbert, T.W.; Badylak, S.F. An overview of tissue and whole organ decellularization processes. Biomaterials 2011, 32, 3233-3243. [CrossRef]

11. Gilbert, T.W.; Sellaro, T.L.; Badylak, S.F. Decellularization of tissues and organs. Biomaterials 2006, 27, 3675-3683. [CrossRef] [PubMed]

12. Moroni, F.; Mirabella, T. Decellularized matrices for cardiovascular tissue engineering. Am. J. Stem Cells 2014, 3, 1-20. [PubMed]

13. Khan, S.; Villalobos, M.A.; Choron, R.L.; Chang, S.; Brown, S.A.; Carpenter, J.P.; Tulenko, T.N.; Zhang, P. Fibroblast growth factor and vascular endothelial growth factor play a critical role in endotheliogenesis from human adipose-derived stem cells. J. Vasc. Surg. 2017, 65, 1483-1492. [CrossRef] [PubMed]

14. Zhou, M.; Liu, Z.; Liu, C.; Jiang, X.; Wei, Z.; Qiao, W.; Ran, F.; Wang, W.; Qiao, T.; Liu, C. Tissue engineering of small-diameter vascular grafts by endothelial progenitor cells seeding heparin-coated decellularized scaffolds. J. Biomed. Mater. Res. B Appl. Biomater. 2012, 100, 111-120. [CrossRef]

15. Villalona, G.A.; Udelsman, B.; Duncan, D.R.; McGillicuddy, E.; Sawh-Martinez, R.F.; Hibino, N.; Painter, C.; Mirensky, T.; Erickson, B.; Shinoka, T.; et al. Cell-seeding techniques in vascular tissue engineering. Tissue Eng. Part B Rev. 2010, 16, 341-350. [CrossRef]

16. Bader, A.; Steinhoff, G.; Strobl, K.; Schilling, T.; Brandes, G.; Mertsching, H.; Tsikas, D.; Froelich, J.; Haverich, A. Engineering of human vascular aortic tissue based on a xenogeneic starter matrix. Transplantation 2000, 70 , 7-14.

17. Bacakova, L.; Zarubova, J.; Travnickova, M.; Musilkova, J.; Pajorova, J.; Slepicka, P.; Kasalkova, N.S.; Svorcik, V.; Kolska, Z.; Motarjemi, H.; et al. Stem cells: Their source, potency and use in regenerative therapies with focus on adipose-derived stem cells-A review. Biotechnol. Adv. 2018, 36, 1111-1126. [CrossRef]

18. Bacakova, L. The Role of Vascular Smooth Muscle Cells in the Physiology and Pathophysiology of Blood Vessels; IntechOpen: Rijeka, Croatia, 2018; pp. 229-257.

19. Vondrášek, D.; Hadraba, D.; Matějka, R.; Lopot, F.; Svoboda, M.; Jelen, K. Uniaxial tensile testing device for measuring mechanical properties of biological tissue with stress-relaxation test under a confocal microscope. Manuf. Technol. 2018, 18, 866-872. [CrossRef]

20. ISO. 11737-2:2019 Sterilization of health care products-Microbiological methods. In Part 2: Tests of Sterility Performed in the Definition, Validation and Maintenance of A Sterilization Process; ISO: Geneva, Switzerland, 2019.

21. Estes, B.T.; Diekman, B.O.; Gimble, J.M.; Guilak, F. Isolation of adipose-derived stem cells and their induction to a chondrogenic phenotype. Nat. Protoc. 2010, 5, 1294-1311. [CrossRef]

22. Bunnell, B.A.; Flaat, M.; Gagliardi, C.; Patel, B.; Ripoll, C. Adipose-derived stem cells: Isolation, expansion and differentiation. Methods 2008, 45, 115-120. [CrossRef]

23. Megaloikonomos, P.D.; Panagopoulos, G.N.; Bami, M.; Igoumenou, V.G.; Dimopoulos, L.; Milonaki, A.; Kyriakidou, M.; Mitsiokapa, E.; Anastassopoulou, J.; Mavrogenis, A.F. Harvesting, Isolation and Differentiation of Rat Adipose-Derived Stem Cells. Curr. Pharm. Biotechnol. 2018, 19, 19-29. [CrossRef]

24. Matejka, R.; Stepanovska, J.; Rosina, J.; Kneppo, P.; Brynda, E.; Riedel, T.; Filova, E.; Travnickova, M.; Zarubova, J.; Riedelova, Z. A Cultivation Chamber for Stimulation of Planar Samples of Decellularized Pericardium; Utility model CZ 30 705; Industrial Property Office: Prague, Czech Republic, 2016.

25. Matejka, R.; Stepanovska, J.; Kneppo, P.; Konarik, M.; Chlupac, J.; Pirk, J. Pressure Stimulation Microperfusion System for Sterile Dynamic Cell Culture; Utility model CZ 33 917; Industrial Property Office: Prague, Czech Republic, 2020.

26. Boccafoschi, F.; Botta, M.; Fusaro, L.; Copes, F.; Ramella, M.; Cannas, M. Decellularized biological matrices: An interesting approach for cardiovascular tissue repair and regeneration. J. Tissue Eng. Regen Med. 2017, 11, 1648-1657. [CrossRef] [PubMed]

27. Melchiorri, A.J.; Bracaglia, L.G.; Kimerer, L.K.; Hibino, N.; Fisher, J.P. In Vitro Endothelialization of Biodegradable Vascular Grafts Via Endothelial Progenitor Cell Seeding and Maturation in a Tubular Perfusion System Bioreactor. Tissue Eng. Part C Methods 2016, 22, 663-670. [CrossRef] 
28. Maul, T.M.; Hamilton, D.W.; Nieponice, A.; Soletti, L.; Vorp, D.A. A New Experimental System for the Extended Application of Cyclic Hydrostatic Pressure to Cell Culture. J. Biomech. Eng. 2007, 129, 110-116. [CrossRef] [PubMed]

29. Lagna, G.; Ku, M.M.; Nguyen, P.H.; Neuman, N.A.; Davis, B.N.; Hata, A. Control of phenotypic plasticity of smooth muscle cells by bone morphogenetic protein signaling through the myocardin-related transcription factors. J. Biol. Chem. 2007, 282, 244-255. [CrossRef] [PubMed]

30. Dan, P.; Velot, É.; Decot, V.; Menu, P. The role of mechanical stimuli in the vascular differentiation of mesenchymal stem cells. J. Cell Sci. 2015, 128, 2415-2422. [CrossRef] [PubMed]

31. Wang, C.; Yin, S.; Cen, L.; Liu, Q.; Liu, W.; Cao, Y.; Cui, L. Differentiation of adipose-derived stem cells into contractile smooth muscle cells induced by transforming growth factor-beta1 and bone morphogenetic protein-4. Tissue Eng. Part A 2010, 16, 1201-1213. [CrossRef]

32. Bacakova, L. Vascular Smooth Muscle Cells (VSMCs) in Blood Vessel Tissue Engineering: The Use of Differentiated Cells or Stem Cells as VSMC Precursors; IntechOpen: Rijeka, Croatia, 2018; pp. 289-308.

33. Miralles, F.; Posern, G.; Zaromytidou, A.I.; Treisman, R. Actin dynamics control SRF activity by regulation of its coactivator MAL. Cell 2003, 113, 329-342. [CrossRef]

34. Kobayashi, N.; Yasu, T.; Ueba, H.; Sata, M.; Hashimoto, S.; Kuroki, M.; Saito, M.; Kawakami, M. Mechanical stress promotes the expression of smooth muscle-like properties in marrow stromal cells. Exp. Hematol. 2004, 32, 1238-1245. [CrossRef]

35. Maul, T.M.; Chew, D.W.; Nieponice, A.; Vorp, D.A. Mechanical stimuli differentially control stem cell behavior. Biomech. Model. Mechanobiol. 2011, 10, 939-953. [CrossRef]

36. Henderson, K.; Sligar, A.D.; Le, V.P.; Lee, J.; Baker, A.B. Biomechanical Regulation of Mesenchymal Stem Cells for Cardiovascular Tissue Engineering. Adv. Healthc. Mater. 2017, 6, 1700556. [CrossRef] [PubMed]

37. Sumpio, B.E.; Widmann, M.D.; Ricotta, J.; Awolesi, M.A.; Watase, M. Increased ambient pressure stimulates proliferation and morphologic changes in cultured endothelial cells. J. Cell Physiol. 1994, 158, 133-139. [CrossRef] [PubMed]

(C) 2020 by the authors. Licensee MDPI, Basel, Switzerland. This article is an open access article distributed under the terms and conditions of the Creative Commons Attribution (CC BY) license (http://creativecommons.org/licenses/by/4.0/). 